\title{
Robustness Analysis of Pull Strategies in Multi-Product Systems
}

\author{
Chukwunonyelum Emmanuel Onyeocha ${ }^{1}$, Joseph Khoury ${ }^{2}$, John Geraghty ${ }^{1}$ \\ ${ }^{1}$ Dublin City University (Ireland) \\ ${ }^{2}$ Methode Electronics Inc. (Germany)
}

cbuks247@gmail.com,joseph.khoury@methodegermany.com,jobn.geraghty@dcu.ie

Received: January 2015

Accepted: July 2015

\section{Abstract:}

Purpose: This paper examines the behaviour of shared and dedicated Kanban allocation policies of Hybrid Kanban-CONWIP and Basestock-Kanban-CONWIP control strategies in multi-product systems; with considerations to robustness of optimal solutions to environmental and system variabilities.

Design/methodology/approach: Discrete event simulation and evolutionary multi-objective optimisation approach were utilised to develop Pareto-frontier or sets of non-dominated optimal solutions and for selection of an appropriate decision set for the control parameters in the shared Kanban allocation policy (S-KAP) and dedicated Kanban allocation policy (D-KAP). Simulation experiments were carried out via ExtendSim simulation application software. The outcomes of PCS+KAP performances were compared via all pairwise comparison and Nelson's screening and selection procedure for superior PCS+KAP under negligible environmental and system stability. To determine superior PCS+KAP under systems' and environmental variability, the optimal solutions were tested for robustness using Latin hypercube sampling technique and stochastic dominance test.

Findings: The outcome of this study shows that under uncontrollable environmental variability, dedicated Kanban allocation policy outperformed shared Kanban allocation policy in serial manufacturing system with negligible and in complex assembly line with setup times. Moreover, the BK-CONWIP is shown as superior strategy to HK-CONWIP. 
Research limitations/implications: Future research should be conducted to verify the level of flexibility of BK-CONWIP with respect to product mix and product demand volume variations in a complex multi-product system

Practical implications: The outcomes of this work are applicable to multi-product manufacturing industries with significant setup times and systems with negligible setup times. The multi-objective optimisation provides decision support for selection of control-parameters such that operations personnel could easily change parameter settings to achieve a new service level without additional optimisations of the system parameters.

Originality/value: The examination of the behaviour of the two Kanban allocation policies in HK-CONWIP and BK-CONWIP in a complex multi-product assembly line with setup-times and environmental variabilities, under erratic demand profiles.

Keywords: multi-product systems, production control strategies, production authorisation cards, multi-objective optimisation, erratic demand, robustness analysis

\section{Introduction}

Pull production control strategies, such as the Kanban Control Strategy (KCS), Base Stock Control Strategy (BSCS), CONWIP and hybrids of these have been widely studied in the literature, predominately in their application to single product manufacturing environments (Baynat, Buzacott \& Dallery, 2002; Bonvik \& Gershwin, 1996; Liberopoulos \& Dallery, 2002). CONWIP and Hybrid Kanban-CONWIP (HK-CONWIP), for instance, have been demonstrated to outperform KCS in manufacturing systems subject to demand variability when the objective is to minimise work-in-process inventory while maximising service level (Geraghty \& Heavey, 2010). Multi-product manufacturing environments are much more difficult to study, especially for optimisation experiments, as they pose several degrees of complexity above single product systems. One practical issue for implementing a pull production control strategy in a multi-product environment stems from the mechanism by which production authorisation cards are allocated to products at various stages in the line. The most common mechanism is the Dedicated Kanban Allocation Policy (D-KAP) where cards are planned separately for each product in the line at each stage or card controlled loop. This policy, inevitably, leads to a proliferation of WIP in a multi-product manufacturing system as quantities of each product type must be maintained in each loop in the line in semi-finished states. To overcome this issue, Baynat et al. (2002) proposed a card allocation mechanism named Shared Kanban Allocation Policy (S-KAP) in which each loop is allocated a single pool of cards shared amongst the product types entering the loop. However, it has been demonstrated in the literature that some existing pull production control strategies cannot operate this mechanism (Baynat et al., 
2002; Onyeocha \& Geraghty, 2012; Olaitan \& Geraghty, 2013) and HK-CONWIP is one of these. Onyeocha and Geraghty (2012) showed that by changing the point at which CONWIP cards are released from completing products and utilising demand cards to initiate production, HK-CONWIP can be modified to operate S-KAP. Furthermore, they also proposed BK-CONWIP, a hybrid of BSCS, KCS and CONWIP, that is capable of operating S-KAP and can respond to demand variations with lower production authorisation cards and lower work-in-process inventory at any targeted service level in a system.

Our experience with the comparison of HK-CONWIP and BK-CONWIP control strategies in multi-product manufacturing systems based on results obtained from multi-objective optimisations and simulation studies on theoretical and empirical case studies shows that S-KAP outperformed D-KAP while BK-CONWIP outperformed HK-CONWIP. Nonetheless, such judgement on the behaviour of these Kanban allocation policies and production control strategies may be premature. According to Kleijnen and Guary (2003), optimisation of a strategy for a certain scenario and making a decision about its performance based on the outcome of the optimal solution of that particular scenario is too risky. A manufacturing system is often subjected to environmental and/or system changes that may include low to high variations in the properties of the distributions of processing times, machine unreliability and demand inter-arrival rates. If these changes are not adequately catered for in a production control strategy, it will result in increased production waste, poor product quality and poor service level. Consequently, it is necessary to create a good solution that is robust to these changes rather than an optimal solution that is sensitive to environmental or system changes.

A few studies that considered D-KAP and S-KAP in multi-product systems such as Olaitan and Geraghty (2013) and Onyeocha, Khoury and Geraghty (2013a, 2013b), did not examine HK-CONWIP in a multi-product environment and none had considered the performance of HK-CONWIP and BK-CONWIP under environmental variability. This paper examines the performance of these two strategies operating a shared or dedicated Kanban allocation policy in the presence of system and environmental instabilities for the purpose of selection and implementation of suitable PCS+KAP in multi-product systems that are prone to environmental and system variabilities. The comparison of the performance of HK-CONWIP and BK-CONWIP was done through the medium of two case studies. The first case study is a similar system studied by Olaitan and Geraghty (2013). It is a health-care serial manufacturing line with negligible set-up times and low to moderate demand variations. The management of the company wishes to select an inventory control strategy that best suits their system for high customer satisfaction. The findings of Olaitan and Geraghty (2013), show that pull strategies are appropriate for such a simple manufacturing system. The second case study is an industrial case from the sponsoring company of a complex assembly line with significant set-up times, erratic demand profiles, highly engineered products with variable batch sizes (small to large), dynamic and complex processes, etc. The management stated that their previous attempts to adopt pull control strategies (KCS and CONWIP) failed and they wish to further evaluate 
inventory control strategies in order to achieve high customer service levels while minimising work-in-process inventory. Studies such as Spearman, Woodruff and Hopp (1990), Marek, Elkins and Smith. (2001), and Krishnamurthy, Suri and Vernon (2004) noted that pull control strategies are effective in simple manufacturing systems operating with low demand variations, repetitive processes and low processing time variations. The findings of Krishnamurthy et al. (2004) showed that pull control strategies perform poor in multi-product systems with varying demands, processing requirements, and highly engineered products in small batches. Therefore, the purpose of using two case studies in this paper is to ascertain the appropriateness of BK-CONWIP and HK-CONWIP in (i) simple manufacturing system operating with low demand variations, repetitive processes, low processing time variations and (ii) complex manufacturing systems with varying demands and highly engineered products in varying batch sizes.

The remainder of this paper is organised as follows: an overview of multi-product manufacturing systems is presented in section 2. The description of the research methodology, experimental conditions and results is described in section 3. The outcomes of the robustness experiments are provided in section 4, while section 5 discusses the results and summaries the findings of the study.

\section{Background}

A growing interest in conducting research studies on multi-product manufacturing systems was recently observed in the literature (Feng, Zheng \& Li, 2012). It was shown that a majority of these studies focused on the scheduling, planning and optimisation issues as well as performance comparison of production control strategies (Onyeocha \& Geraghty, 2012; Onyeocha et al., 2013a). Akurk and Erhun (1999), Hum and Lee (1998) and Chern, Lei and Huang (2014) developed methods for solving planning and scheduling issues in multi-product environments such that it proffers a solution when two or more product-types waiting in a queue require a decision to determine the product-type to release first into a system. Similarly, Park and Lee (2013) proposed an approximation technique for analysing a multi-product CONWIP system having correlated external demands. Bard and Golany (1991) proposed a mathematical model for optimisation of the number production authorisation cards to reduce the inventory, production and shortage costs in a multi-product system. Furthermore, Satyam and Krishnamurthy (2008), Duenyas (1994), Ryan, Baynat and Choobineh (2000), Ryan and Vorasayan (2005) examined the influence of the WIP cap of CONWIP in multi-product manufacturing systems. Gurgur and Altiok (2008) investigated multi-stage multi-product systems that implement a two-card Kanban control strategy. Their study proposed an approximation algorithm to analyse work-in-process inventory and service levels for individual 
product-types. Similarly, Li and Huang (2005) developed a recursive method to evaluate a split and merge process in multi-product systems.

Conversely, studies that considered changeovers and/or finite buffer sizes in multi-product environments are limited in the literature (Feng et al., 2012). Altiok and Shiue (2000) analysed a one-machine multi-product system with sequence-independent changeovers. Krieg and Kuhn (2002, 2004) examined multi-product systems with sequence-independent changeovers, cyclic scheduling policy and Kanbans. Hernandez-Matias, Vizan, Hidalgo and Rios (2006) integrated manufacturing process analysis into a modelling framework reducing the time use in analysis of complex systems. Dasci and Karakul (2008) evaluated a multi-product system with finite buffers and sequence-dependent changeovers by means of an iterative approach. Feng, Zheng and $\mathrm{Li}$ (2011) studied the performance of a multi-product system with sequence-dependent changeovers, finite buffer and a cyclic policy. These studies provided meaningful insights on the effect of finite buffers and changeovers in multi-product systems. Onyeocha et al. (2013a) reported a growing attention on the effect of Kanban allocation policies on pull production control strategies in multi-product systems. Baynat et al. (2002) proposed a Kanban allocation policy that is capable of sharing resources among product-types in multi-product systems. Their paper described the concept and application of the two Kanban allocation policies for the control mechanism of a multi-product pull production control strategies and it was shown that the shared Kanban allocation policy (S-KAP) outperformed the dedicated Kanban allocation policy (D-KAP). However, the paper noted that the Kanban control strategy does not naturally operate in S-KAP mode. Likewise, Olaitan and Geraghty (2013) evaluated the performance of five pull production control strategies operating D-KAP and/or S-KAP on a two-product, three-stage multi-product manufacturing system with a minimal blocking policy, negligible setup times and similar, unreliable machines. Their findings showed that the Generalised Kanban Control Strategy (GKCS) operating S-KAP outperformed the other strategies and policies examined when a robust system was not required. However, when the decision maker required a robust solution the Extended Kanban Control Strategy (EKCS) with D-KAP was preferred. They also reported that CONWIP and the Base Stock Control Strategy (BSCS) will not naturally operate in S-KAP mode.

A review of the literature in theoretical studies on manufacturing systems shows little considerations to robustness of solutions, whereas in real world scenarios, where system and environmental changes are inevitable, robustness of a solution is vital to maintain solution stability. According to Feng et al. (2012), a few research studies have focused on specific issues that influence optimal solutions to provide insight on the effect of robustness of a solution in manufacturing systems. Some of the areas of interest include the input data variations, estimation error, and deficiency of data and the design of repair/rework systems. Kang and Gershwin (2005) studied the effect of erroneous data in inventory systems. The outcome of their study shows that a minimal possibility of stock loss negatively impacts the replenishment process resulting in severe stock-outs in a system. Feit and Wu (2000) 
investigated the effect of uncertainty in machine performance on the design of a transfer line. The paper suggested an analytical approach to minimise uncertainty via identification of the critical data for total design performance. Li et al. (2005) proposed a simple approximation method for the estimation of the reliability data of feeder lines, which were shown to improve the accuracy of the throughput estimation. Similarly Li, Blumenfeld and Marin $(2007,2008)$ conducted robustness analysis on the design of repair and rework systems in an automotive paint shop. The paper showed that robustness analysis improves the outcome and quality of products in a system. Related studies on robust designs of systems include Kleijnen and Gaury (2003); Moeeni, Sanchez and Vakharia (1997); Saitou, Malpathak and Qvam (2002); and Taguchi (1987). However, these studies addressed issues relating to single product manufacturing environments with the postulation that their findings are scalable to multi-product manufacturing systems. Studies on robustness analysis in multi-product systems include the works of Feng et al. (2012) and Olaitan and Geraghty (2013). Feng et al. (2012) examined the robustness of scheduling policies in multi-product systems with finite buffers and sequence-dependent changeover times. The findings of their study proposed that the cyclic policy (machine processing product-types in the order of 1,2 , ...to the last product-type and back again to $1,2 .$. ) and longest queue policy (machine always switches to product-type with the longest queue) show relatively robust and/or good performance over a wide range of varying parameters.

Regardless of the studies of Feng et al. (2012) and Olaitan and Geraghty (2013) on multi-product systems, further insight is required regarding the performance of shared and dedicated Kanban allocation policies and the pull production control strategy with consideration to instability in different multi-product manufacturing systems. This paper focuses on the robustness analysis of the two Kanban allocation policies and the two pull production control strategies (HK-CONWIP and BK-CONWIP) in a two-product three-stage serial manufacturing line and a complex four-product five-stage assembly line with sequence-dependent changeover times, finite buffers and erratic demand profiles.

\section{Experimental Methodology}

The methodology for investigating the application and behaviour of the pull production control strategies in multi-product manufacturing systems and the effect of the control factors on their performance metrics such as the level of work-in-process inventory and the delivery performance (service level and/or backlogs) used in this paper are primarily classified as (i) modelling (ii) simulation based optimisation and (iii) comparison techniques. In modelling, various significant entities, components, interactions between components of a system and the performance metrics are identified and theoretical designs are developed. The theoretical design is translated into a simulation model. ExtendSim V8 was used to develop the simulation 
models. A multi-objective optimisation block for ExtendSim developed by Kernan and Geraghty (2004) was used to conduct all optimisation experiments. To determine a superior PCS+KAP, significant analyses and comparisons of experimental results are required. The techniques and tools used in this study include (i) the Pareto optimisation curvature analysis via a curvature function, (ii) all pairwise comparison and Nelson's screening and selection procedure for ranking and selection of the best system, (iii) robustness analysis via the Latin hypercube sampling technique and stochastic dominance test.

In this section, a brief description of the two systems modelled and their configurations are presented. It provides details of the modelling assumptions, which were used to model the system entities and interactions that influence the performance of the systems. Additionally, the performance metrics and the analytical methods for comparing the performances of each PCS+KAP with respect to these metrics without and with consideration for robustness to environmental variations are presented here.

\subsection{System Description}

The two-product three stage manufacturing system used in this paper was similar to the one described by Olaitan and Geraghty (2013), whereas the four-product five stage assembly line was a case-study of a highly automated electronics component manufacturing plant. The two-product three-stage serial manufacturing line with negligible setup times (see, Figure 1) hereinafter referred to as case-1, is a theoretical study, used here to provide fundamental understanding of the concept and relationship of predictable demand and system variables in simple multi-product manufacturing lines. Case-1 operates a low to high demand variability and was planned to deliver a targeted service level with the least possible work-in-process inventory. The system has infinite buffer capacity, no priority, and no set-ups. The unreliability of the system follows a Markovian distribution of the Mean Time Between Failures (MTBF) and Mean Time To Repair (MTTR) at 90 hours and 10 hours, respectively. The processing times of the machines are deterministic, while the mean time between demands is normally distributed. A description of the system configuration data is presented in Table 1 . Conversely, the complexity of most real world multi-product manufacturing systems, with the need for minimisation of the number of set-ups, minimisation of the run/batch quantity and dynamic priority control to meet order due dates, are not considered in case-1. These complexities in real world systems create a gap between theoretical and industrial case studies. To understand the behaviour of a real world complex multi-product manufacturing system, an industrial automotive component manufacturing facility producing four products in a five-stage assembly line with significant set-up times, finite buffer sizes, dynamic priority, part-type production sequence and time, adjustable run/batch quantity and operator shifts, hereinafter referred to as case-2 (see, Figure 2) was used. The five stages are grouped in three cells with cell 1 
consisting of two assembly processes (stages 1 and 2), cell 2 consists of a welding process (stage 3), while cell 3 consists of a final assembly process and a quality control process (stages 4 and 5). The demand is erratic in nature and is uncertain.

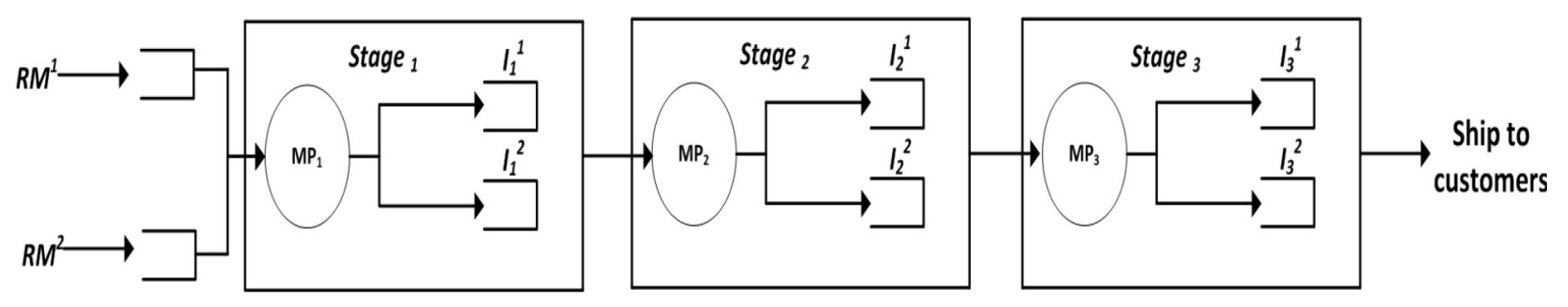

Figure 1. Case-1 two-product three-stage manufacturing system

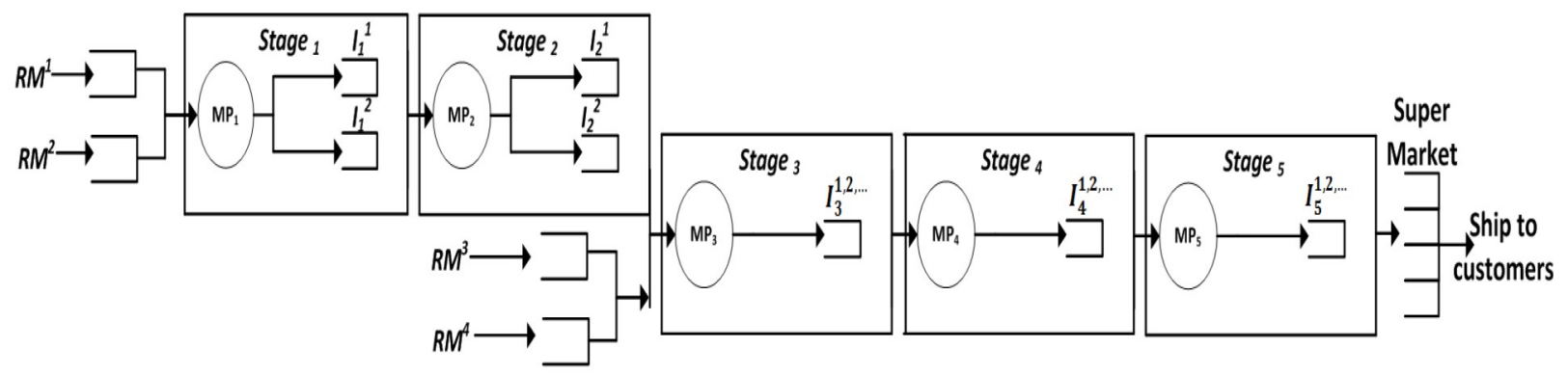

Figure 2. Case-2 four-product five-stage manufacturing system

In Figures 1 and 2, $R M^{i}$ denotes raw material where $i$ is part type $=1,2$ for Figure 1 and $i=1,2,3,4$ for Figure 2, MP represents manufacturing process unit where $j$ is stage number $=1,2,3$ for Figure 1 and $j=1,2,3,4,5$ for Figure 2, $I_{j}^{i}$ symbolises inventory of part type in a stage where $i$ is part type and $j$ is stage number. Table 2 provides a description of the symbols and acronyms used in this paper.

\begin{tabular}{|c|c|c|c|c|}
\hline \multirow{2}{*}{ Stage } & Product 1 & Product 2 & \multirow{2}{*}{$\begin{array}{l}\text { MTBF Exponential } \\
\text { Distribution Mean }\end{array}$} & \multirow{2}{*}{$\begin{array}{l}\text { MTTR Exponential } \\
\text { Distribution Mean }\end{array}$} \\
\hline & Processing Time & Processing Time & & \\
\hline 1 & 1.5 hours & 3 hours & 90 hours & 10 hours \\
\hline 2 & 1.5 hours & 3 hours & 90 hours & 10 hours \\
\hline 3 & 1.5 hours & 3 hours & 90 hours & 10 hours \\
\hline Demand & $\sim N(5.61,2.805)$ & $\sim N(5.72,0.572)$ & & \\
\hline
\end{tabular}

Table 1. Case-1 manufacturing system configuration 


\begin{tabular}{|l|l|l|l|}
\hline Symbol & Description & Symbol & Description \\
\hline$I^{1,2, \ldots}$ & Inventory buffer for product $1,2, \ldots$ & $R M_{1,2, \ldots}$ & Raw material for stage $1,2, \ldots$ \\
\hline$I_{1,2, \ldots}^{1, \ldots}$ & $\begin{array}{l}\text { Inventory buffer for product } 1,2, \ldots \text { at } \\
\text { stage } 1,2, \ldots\end{array}$ & $M P_{1,2, \ldots}$ & Manufacturing process unit at stage $1,2, \ldots$ \\
\hline Acronym & Description & Acronym & Description \\
\hline PCS & Production Control Strategy & KAP & Kanban Allocation Policy \\
\hline BK-CONWIP & $\begin{array}{l}\text { Basestock Kanban CONWIP control } \\
\text { strategy }\end{array}$ & D-KAP & Dedicated Kanban Allocation Policy \\
\hline HK-CONWIP & Hybrid Kanban CONWIP control strategy & S-KAP & Shared Kanban Allocation Policy \\
\hline CONWIP & Constant Work In Process control strategy & PCS+KAP & $\begin{array}{l}\text { A specified KAP and specified PCS } \\
\text { combination }\end{array}$ \\
\hline BSCS & Basestock Control Strategy & WIP & Work In Process inventory \\
\hline KCS & Kanban Control Strategy & PAC & Production Authorisation Card \\
\hline PPCS & Pull production control strategy & & \\
\hline
\end{tabular}

Table 2. Description of symbols and acronyms used in this paper

In case-2, there are two product families and each of the families has two products. The family-1 products enter the system at stage- 1 , while family- 2 products enter the system at stage 3. The last three stages in the assembly line have significant changeover times, while all the stages in the assembly line are subject to random failure. The machines are dissimilar and the processing times of parts vary between families, but are similar for products of the same family. Finished products are stored in a supermarket and supplies are made to customers in box quantities on a two hourly period. The box quantity of family-one products contains 90 parts while the box of family-two products contains 120 parts. The demands for product-types are random and unpredictable, while the order due date is equivalent to the company's production week period.

The demand profile of the system, referred to as Demand Data Set, was collected from the company and it comprises of six production weeks' demand, referred to as week 1-6. Table 3 provides a description of the demand profile for the six weeks' view, while the system configuration is presented in Table 4.

\begin{tabular}{|c|c|c|c|c|c|c|}
\hline $\begin{array}{c}\text { Demand Data } \\
\text { Set }\end{array}$ & $\begin{array}{c}\text { Week 1 } \\
\text { Number of } \\
\text { boxes }\end{array}$ & $\begin{array}{c}\text { Week 2 } \\
\text { Number of } \\
\text { boxes }\end{array}$ & $\begin{array}{c}\text { Week 3 } \\
\text { Number of } \\
\text { boxes }\end{array}$ & $\begin{array}{c}\text { Week 4 } \\
\text { Number of } \\
\text { boxes }\end{array}$ & $\begin{array}{c}\text { Week 5 } \\
\text { Number of } \\
\text { boxes }\end{array}$ & $\begin{array}{c}\text { Week 6 } \\
\text { Number of } \\
\text { boxes }\end{array}$ \\
\hline Product 1 & 542 & 452 & 404 & 503 & 247 & 483 \\
\hline Product 2 & 130 & 224 & 142 & 118 & 129 & 114 \\
\hline Product 3 & 130 & 184 & 131 & 159 & 125 & 147 \\
\hline Product 4 & 110 & 138 & 147 & 71 & 61 & 39 \\
\hline
\end{tabular}

Table 3. Case-2 demand dataset 


\begin{tabular}{|c|c|c|c|c|c|c|c|}
\hline \multirow{2}{*}{ Stage } & Product 1 & Product 2 & Product 3 & Product 4 & \multicolumn{2}{|c|}{$\begin{array}{c}\text { Maintenance: Exponential } \\
\text { Distribution Mean }\end{array}$} & Setup Times (Hours) \\
\cline { 2 - 7 } & $\begin{array}{c}\text { Processing } \\
\text { Times/ Box } \\
\text { (Hours) }\end{array}$ & $\begin{array}{c}\text { Processing } \\
\text { Times/Box } \\
\text { (Hours) }\end{array}$ & $\begin{array}{c}\text { Processing } \\
\text { Times/Box } \\
\text { (Hours) }\end{array}$ & $\begin{array}{c}\text { Processing } \\
\text { Times/Box } \\
\text { (Hours) }\end{array}$ & $\begin{array}{c}\text { MTBF } \\
\text { (Hours) }\end{array}$ & $\begin{array}{c}\text { MTTR } \\
\text { (Hours) }\end{array}$ & \\
\hline 1 & 0.162 & 0.162 & 0 & 0 & 3.5 & 0.23 & 0 \\
\hline 2 & 0.126 & 0.126 & 0 & 0 & 3.5 & 0.23 & 0 \\
\hline 3 & 0.0975 & 0.0975 & 0.13 & 0.13 & 6.1 & 0.23 & $N \sim(0.327,0.109)$ \\
\hline 4 & 0.0975 & 0.0975 & 0.13 & 0.13 & 6.1 & 0.23 & $N \sim(0.327,0.109)$ \\
\hline 5 & 0.0975 & 0.0975 & 0.13 & 0.13 & 6.1 & 0.23 & $N \sim(0.327,0.109)$ \\
\hline
\end{tabular}

Table 4. Case-2 manufacturing system configuration settings

\subsection{Simulation Modelling}

A simulation is a technique widely used in analysis of complex systems and has several advantages over analytic techniques (Koulouriotis, Xanthopoulos \& Tourassis, 2010; Khojasteh-Ghamari, 2009). It has been applied in modelling manufacturing systems and optimisation of system parameters in computing control variables with smaller amount estimations (Lin \& Chen, 2015). In modelling manufacturing system, object-oriented simulations are widely used to design and configure the control parameters of the system. The configured control parameters of a modelled manufacturing system determine the behaviour and performance the system. Hence, a system with an optimal control parameter will perform relatively its best when the system is not subject to environmental or system variations (Koulouriotis et al., 2010). The optimal control parameters of pull control strategies are mainly the processing times, machine unreliability, minimum number of the production authorisation cards of the strategies that achieves the maximum throughput while maintaining the minimum work in the system. ExtendSim simulation; an object-oriented modelling and simulation tool from Imagine That Inc. (www.extendsim.com) was used in this study to develop the manufacturing system and conduct optimisation of the control parameters. It allows the modelling of entities, the interactions, events and setting of control parameters such as the input and manufacturing process variables (production authorisation cards, simulation time, buffer control policies, setup minimisation functions, setup times, processing times, quantity, demand arrival, distributions, etc.,) output variables (data collection processes for WIP, Service level, etc.) and their interactions with each other.

We designed the conceptual model of the manufacturing system layout and had a technical walk-through of the systems' entities and their interactions. The designed models were translated into simulation models using the ExtendSim blocks (objects) representing these entities. The fundamental stages followed in translating the conceptual models into simulation models are identification of the entities, constructing the architectural level of the entities in the layout, and connecting the entities to interact with each other as the real systems. The simulation models were verified and validated to ensure that the models are true 
representation of the systems. The models were verified by technical walk-through of the entities and their interactions. The models captured accurately the systems' entities and linkages. The models were validated owing to the contents of the systems and by direct comparison with the output of models found in the works of Olaitan and Geraghty (2013) and Onyeocha et al. (2013a, 2013b). Furthermore, the models were operated using a simple push control strategy for which the systems are being operated and the output data collected were affirmed by the company's production team as valid. Therefore, the models were adopted for this study as a true representation of the systems.

\subsubsection{Modelling Assumptions}

The following assumptions were made to simplify case-1 system for modelling:

- The system produces two products in a three stage serial line using similar machines.

- Demand profile is stochastic in nature and unfulfilled demand in a period is recorded as backlog and served in the following period.

- The three stages in the system are supposed to have negligible setup, infinite buffer size and first-in-first-out buffer order.

- Raw materials are considered as always available and the machines are assumed to have operations-dependent failure.

- The transfer time (including loading and unloading times) is negligible.

- Negative output generated from normal distribution used in modelling the demand arrival occurrence will immediately create arrival of demand.

The assumptions to simplify case- 2 system for modelling are as follows:

- Four products of two families are produced in an assembly line.

- Raw materials are assumed to be always available.

- The system comprises of five stages, a component manufacturing unit and a supermarket.

- The component manufacturing unit is considered as raw material unit.

- Unfulfilled demands are considered as backlog at the end of each production week and served in the following production week. 
- A production week is considered as 120 hours.

- The system has sequence-dependent changeovers, finite buffer size, priority buffer order and dynamic changeover factor

- Changeover is assumed to occur in stages 3 to 5 areas, such that stages 3 to 5 undergo clearance and remain down pending when the stages recover from changeover.

- Machine failure is operation-dependent

\subsection{Performance Measures}

One of the widely used performance metrics in comparison of pull production control strategies is the trade-off points between the average work-in-process inventory and the average service level (see, Olaitan and Geraghty, 2013, Khojasteh-Ghamari, 2009, Geraghty and Heavey, 2005 and Bonvik, Christopher \& Gershwin, 1997). Olaitan and Geraghty (2013) and Geraghty and Heavey (2005) centred their evaluation of various pull production control strategies on the proportion of work-in-process inventory level used by a production control strategy in a system to achieve a targeted service level. For the purpose of comparison, a minimum work-in-process inventory that achieves $100 \%$ service level in the system is used in this paper. This study was conducted such that the outcome, based on the two systems will provide insight on the behaviour and relationship of the performance of the pull production control strategies and Kanban allocation policies in a simply theoretical serial flow line and a complex real-world assembly line.

\subsection{Control Mechanisms}

The control mechanisms for BK-CONWIP in both S-KAP and D-KAP mode are provided in Onyeocha et al. (2013a; 2013b). The control mechanism for HK-CONWIP in D-KAP mode is provided in Onyeocha and Geraghty (2012). According to Onyeocha and Geraghty (2012), HK-CONWIP is incapable of naturally operating S-KAP. The modification approach suggested in their paper was applied to HK-CONWIP to develop HK-CONWIP S-KAP. The control mechanism of HK-CONWIP S-KAP is similar to HK-CONWIP D-KAP except that a CONWIP card is detached from a part after it completes processing at final stage in the line. The CONWIP cards are returned to a shared resource pool to wait for demand information card for any product type, while the finished part enters the Finished Goods Inventory or Supermarket. When a demand occurs in a system, a demand information card is sent upstream to batch with a CONWIP card to authorise the release of the required product type into the system and a corresponding demand information card is sent to the final goods inventory to release a product to satisfy the 
demand. If a product of the required type is not available in the final goods inventory the demand is backlogged. If a CONWIP card is not available, the part replenishment process is delayed.

Furthermore, it is noted here that the priority rule in place at the third stage in case- 2 presents an additional modification of HK-CONWIP which normally assumes no internal transmission of demand information. The priority rule, for job selection at stage 3, gives priority to Family $A$ products in the first 2 days of production week, to Family B products in the third day and equal priority in the remaining 2 days. Additionally, the priority rule will select among products based on demand performance. For example, on the first and second day in a production week, priority will be given to Family A products and if inventory of both products from this family is available the product with the lowest percentage of its weekly demand produced through stage 3 will be selected. Essentially, this introduces demand information to the line at stage 3, which is delayed owing to the minimum batch/run quantity that is used to specify the minimum time to a changeover when WIP is available.

\subsection{Optimisation and Pareto Frontier Curvature Analysis}

Real-world manufacturing systems' problems often contain two or more conflicting objectives resulting in a complex search space (Hwang \& Masud 1979). In such cases a multi-objective optimisation approach is often favoured as it searches for optimality in problems with multiple conflicting objectives, which often results in the generation of a set of solutions that are insensitive to each solution, implying that no enhancement can be achieved by altering any of the constraints without negatively influencing the performance of one or more of the objectives (Hwang \& Masud 1979; Horn 1997). This set of non-dominated solutions is referred to as the Pareto-optimal solution frontier. The combination of search and decision making in multi-objective optimisation into one optimisation condition has an advantage over single-objective optimisation approach and can be useful without additional modifications (Hwang \& Masud 1979; Horn 1997). A multi-objective optimisation application block called the Pareto optimiser for ExtendSim developed by Kernan and Geraghty (2004) was adopted for conducting a multi-objective space search via genetic algorithms in this paper. The purpose of the multi-objective optimisation approach is to determine the trade-off points between conflicting objectives. 
The trade-off curves of all PCS+KAP obtained from the Pareto optimisation were analysed using the curvature function $k$, which measures the rate of change of the curve to the direction of a tangent and is given by:

$$
k=\frac{\frac{d^{2} y}{d x^{2}}}{\left[1+\left(\frac{d y}{d x}\right)^{2}\right]^{\frac{3}{2}}}
$$

The negative or positive sign of the curvature function $k$ shows the direction of rotation of the unit tangent vector along the curve, such that a clockwise rotation of the unit tangent vector indicates that $k<0$, while a counter clockwise rotation of the unit tangent indicates that $k>0$. This technique is used in this paper to compute the points of inflection and the corresponding service level.

\subsection{Comparison of Systems without Consideration for Robustness}

In order to compare the performances of the PCS+KAP alternatives for each case the methodology of Olaitan and Geraghty (2013) is adopted here. Firstly, an all-pairwise comparison of the performance of each system for minimum WIP required to achieve targeted Service Levels (95\%, 98\% and 100\%) was used to explore the comparative performances of pairs of PCS+KAP for each case. Furthermore, a ranking and selection technique proposed by Nelson, Swann, Goldsman and Song (2001) was utilised to validate the results obtained from direct observation and all pairwise comparison. The procedure authorises the removal of poorer performing PCS+KAP during screening without additional simulations. Survivors of the screening are gathered into a set for further comparison based on additional simulations. However, if the survivors' set contains only one survivor, it is selected as the superior PCS+KAP. The average total work-in-process inventory level and the average total service level of the pull production control strategies and Kanban allocation policies were screened.

\subsection{Comparison of Systems with Consideration for Robustness}

The robustness analysis method of Kleijnen and Gaury (2003) was adopted in this study to analyse the effects of environmental variations in a multi-product manufacturing system under the control of HK-CONWIP or BK-CONWIP. The procedure uses a statistical technique for generating feasible sets of control settings or factors from a multi-dimensional distribution known as Latin Hypercube Sampling (LHS). A minimum of 100 samples are required for the LHS robustness analysis procedure (Kleijnen \& Gaury, 2003; Olaitan \& Geraghty, 2013). The comparisons of strategies are performed via a stochastic dominance test on the outcomes of their cumulative distribution functions. The outcome of a stochastic dominance test is reported 
as first or second degree dominance or in some cases inconclusive based on the level of the significant difference between the compared strategies. For instance, assuming that the cumulative distribution functions of two systems $A$ and $B$ are given by $P_{A}(x)$ and $P_{B}(x)$. If the objective of the stochastic dominance test is to maximise the value of $x$, then system $A$ is said to have first-order stochastic dominance over system $B$ if

$$
P_{A}(x) \leq P_{B}(x), \text { for all } x
$$

While system $A$ stochastically dominates system $B$ in a second order degree if:

$$
\int_{a}^{k} P_{A}(x) d x \leq \int_{a}^{k} P_{B}(x) d x, \text { for all } k
$$

In cases where there are insignificant difference between system $A$ and $B$, the stochastic dominance test returns as inconclusive.

\section{Experimental Results}

This section will, firstly, provide results from the application of the multi-objective optimisation algorithm for all PCS+KAP for each case. The curvature analysis of each Pareto frontier generated is also provided. The section will also detail the results of experiments conducted to compare the performances of the PCS+KAP for both cases without and with consideration for robustness to system and environmental variability.

\subsection{Results from Optimisation and Pareto Frontier Curvature Analysis}

A mutation rate of $10 \%$ was selected for the experiments, while the number of generations before terminating the search was set at 150 generations and the number of replications was set to 30. Trial runs were conducted using arbitrary values to find suitable search range settings that can achieve service levels between $80 \%$ and $100 \%$. The simulation run length is 50000 hours for case 1 and 1200 hours for case. In case 2, in addition to the parameters of the PCS+KAP, a changeover parameter is also considered in the optimisation. The changeover parameter identifies the minimum number of batches of a product to be produced, subject to availability of inventory, before a changeover can be considered. This parameter is set so as to avoid frequent changeovers and mirrors the company's own changeover policy. In case 1, a search space ranging from 1 to 50 was used in determining the optimal values for the production authorisation cards (Kanban and CONWIP), while in case 2, the search space was between 1 and 350. A summary of the optimal values of the control parameters that achieve 95\% service level is presented in Tables 5 and 6. 


\begin{tabular}{|c|c|c|c|c|c|c|c|c|}
\hline \multicolumn{9}{|c|}{ Pareto Decision Set at $\mathbf{9 5} \%$ Service Level } \\
\hline PCS & KAP & Product & $\begin{array}{c}\text { Search } \\
\text { range }\end{array}$ & S1 Kanban & S2 Kanban & S3 Kanban & $\begin{array}{c}\text { Total } \\
\text { Kanban }\end{array}$ & CONWIP \\
\hline \multirow{4}{*}{ HK-CONWIP } & \multirow{2}{*}{ D-KAP } & 1 & $1-50$ & 11 & 12 & N/A & 23 & 20 \\
\hline & & 2 & $1-50$ & 10 & 10 & N/A & 20 & 17 \\
\hline & \multirow{2}{*}{ S-KAP } & 1 & \multirow{2}{*}{$1-50$} & \multirow{2}{*}{20} & \multirow{2}{*}{22} & \multirow{2}{*}{ N/A } & \multirow{2}{*}{42} & \multirow{2}{*}{33} \\
\hline & & 2 & & & & & & \\
\hline \multirow{4}{*}{ BK-CONWIP } & \multirow{2}{*}{ D-KAP } & 1 & $1-50$ & 12 & 11 & N/A & 23 & 19 \\
\hline & & 2 & $1-50$ & 10 & 9 & N/A & 19 & 13 \\
\hline & \multirow{2}{*}{ S-KAP } & 1 & \multirow{2}{*}{$1-50$} & \multirow{2}{*}{22} & \multirow{2}{*}{19} & \multirow{2}{*}{ N/A } & \multirow{2}{*}{41} & \multirow{2}{*}{31} \\
\hline & & 2 & & & & & & \\
\hline
\end{tabular}

S: Stage; N/A: Not Applicable.

Table 5. Case-1 Search space and optimal values of PCS+KAP at $95 \%$ service level

\begin{tabular}{|c|c|c|c|c|c|c|c|c|c|}
\hline \multicolumn{10}{|c|}{ Pareto Decision Set at $95 \%$ Service Level } \\
\hline PCS & KAP & Product & $\begin{array}{c}\text { Search } \\
\text { range }\end{array}$ & $\begin{array}{c}\text { C1 } \\
\text { Kanban }\end{array}$ & $\begin{array}{c}\text { C2 } \\
\text { Kanban }\end{array}$ & $\begin{array}{c}\text { C3 } \\
\text { Kanban }\end{array}$ & $\begin{array}{c}\text { Total } \\
\text { Kanban }\end{array}$ & CONWIP & $\begin{array}{l}\text { Changeover } \\
\text { Parameter } \\
\text { Setting }\end{array}$ \\
\hline \multirow{8}{*}{ HK-CONWIP } & \multirow{4}{*}{ D-KAP } & 1 & $1-350$ & 8 & 10 & N/A & 18 & 116 & 6 \\
\hline & & 2 & $1-350$ & 7 & 6 & N/A & 13 & 40 & 4 \\
\hline & & 3 & $1-350$ & N/A & 7 & N/A & 7 & 19 & 4 \\
\hline & & 4 & $1-350$ & N/A & 6 & N/A & 6 & 30 & 3 \\
\hline & \multirow{4}{*}{ S-KAP } & 1 & \multirow{4}{*}{$1-350$} & \multirow{2}{*}{9} & \multirow{2}{*}{9} & N/A & \multirow{2}{*}{18} & \multirow{4}{*}{202} & 5 \\
\hline & & 2 & & & & N/A & & & 2 \\
\hline & & 3 & & N/A & \multirow{2}{*}{8} & N/A & \multirow{2}{*}{8} & & 2 \\
\hline & & 4 & & N/A & & N/A & & & 5 \\
\hline \multirow{8}{*}{ BK-CONWIP } & \multirow{4}{*}{ D-KAP } & 1 & $1-350$ & 8 & 10 & N/A & 18 & 140 & 6 \\
\hline & & 2 & $1-350$ & 6 & 6 & N/A & 12 & 50 & 4 \\
\hline & & 3 & $1-350$ & N/A & 7 & N/A & 7 & 19 & 5 \\
\hline & & 4 & $1-350$ & N/A & 6 & N/A & 6 & 21 & 3 \\
\hline & \multirow{4}{*}{ S-KAP } & 1 & \multirow{4}{*}{$1-350$} & \multirow{2}{*}{6} & \multirow{2}{*}{5} & N/A & \multirow{2}{*}{11} & \multirow{4}{*}{161} & 7 \\
\hline & & 2 & & & & N/A & & & 3 \\
\hline & & 3 & & N/A & \multirow{2}{*}{8} & N/A & \multirow{2}{*}{8} & & 5 \\
\hline & & 4 & & N/A & & N/A & & & 5 \\
\hline
\end{tabular}

N/A: Not Applicable; C: cell; $C 1=$ stages 1 and $2 ; C 2=$ stage $3 ; C 3=$ stages 4 and 5.

Table 6. Case-2 Search space and optimal values of PCS+KAP at 95\% service level

The Pareto frontiers, showing the trade-off points between the average work-in-process inventory and the service levels achieved by individual PCS+KAP, are presented in Figures 3 and 4 for case 1 and case 2, respectively. The Pareto frontiers in this paper will concentrate on Service Levels above $90 \%$ as industrialists are interested in achieving higher service levels. 


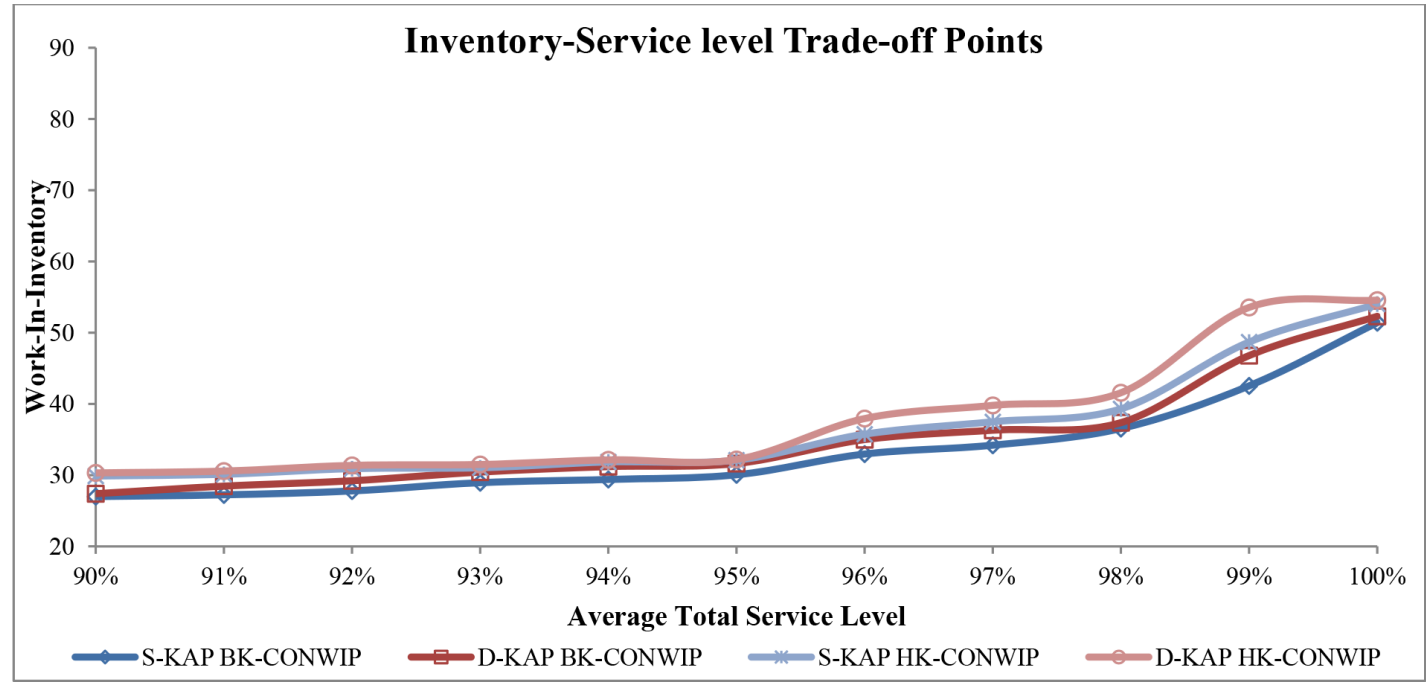

Figure 3. Trade-off between service level and inventory (Case 1)

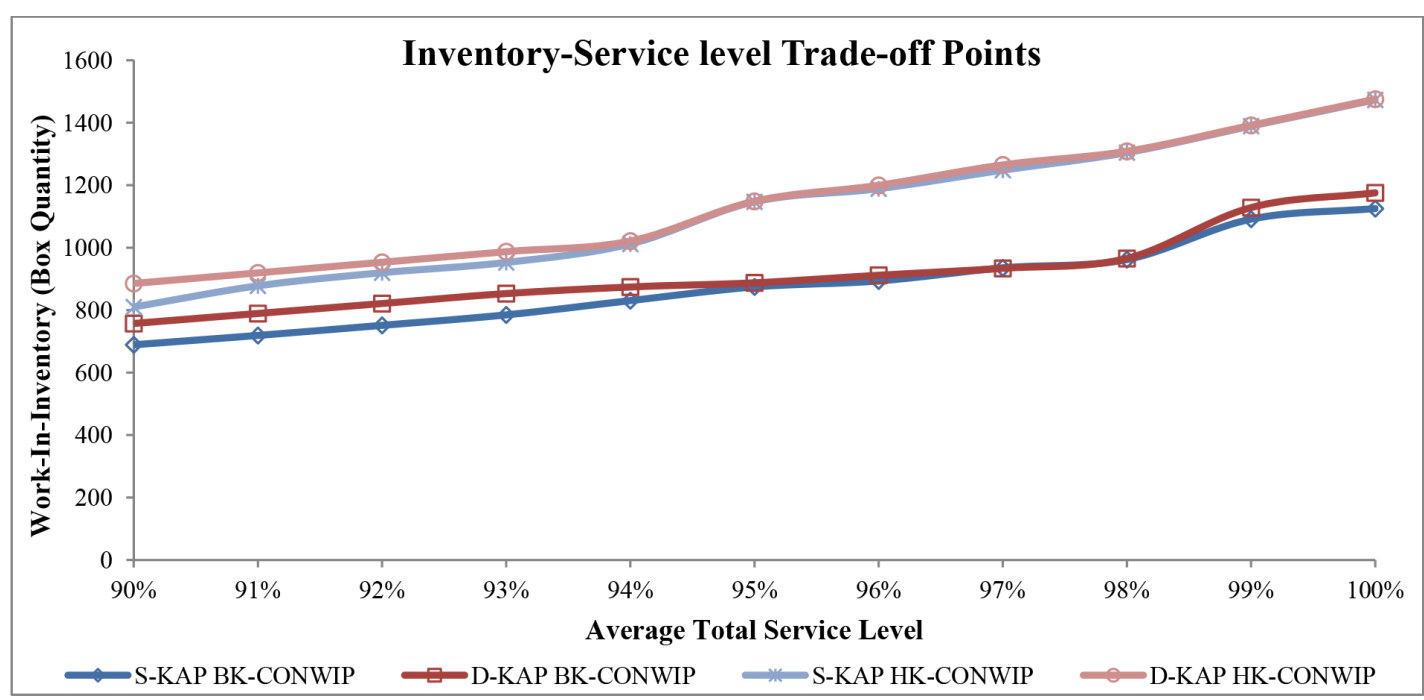

Figure 4. Trade-off between service level and inventory (Case 2)

The results of the application of the curvature function technique on the Pareto optimisation curve (Figures 3 and 4 ) of the PCS+KAP in cases 1 and 2 (for the curvature for the average total work-in-process inventory and the average service level) suggest that the decision makers should set the parameters of PCS+KAP to achieve the performance metrics shown in Table 7 


\begin{tabular}{|c|c|c|c|}
\hline Case Type & PCS+KAP & Average TSL (\%) & Average TWIP \\
\hline \multirow{4}{*}{ Case 1 } & BK-CONWIP D-KAP & 98 & 37.37 \\
\cline { 2 - 4 } & BK-CONWIP S-KAP & 98 & 36.54 \\
\cline { 2 - 4 } & HK-CONWIP D-KAP & 95 & 32.20 \\
\cline { 2 - 4 } & HK-CONWIP S-KAP & 95 & 32.10 \\
\hline \multirow{4}{*}{ Case 2 } & BK-CONWIP D-KAP & 98 & 965.41 \\
\cline { 2 - 4 } & BK-CONWIP S-KAP & 98 & 961.90 \\
\cline { 2 - 4 } & HK-CONWIP D-KAP & 94 & 1021.04 \\
\cline { 2 - 4 } & HK-CONWIP S-KAP & 94 & 1011.85 \\
\hline
\end{tabular}

Table 7. Performance metrics achievable at low WIP cost

Table 7 shows the inflection points of each PCS+KAP such that the cost of increasing the service level becomes more expensive in terms of the proportion of WIP required achieving such an increased service level. The results of the Pareto frontier curves analysis show that the S-KAP models in both cases outperformed the D-KAP models. BK-CONWIP S-KAP is superior to the other models because it maintained lower work-in-process inventory level throughout the curve. The HK-CONWIP D-KAP model maintained the highest work-in-process inventory, making it the worst system among the models in case 1 and case 2 . The poor performance of D-KAP is largely attributed to the large number of the total authorisation cards that are used in releasing product-types into the system. The large amount of released product-types increases the work-in-process inventory in the system. Additionally, when considering the curvature functions of each Pareto frontier, the rate of change of the angle of the Pareto frontier is slower in S-KAP models than the D-KAP models.

\subsection{Analysis of Performance without Consideration for Robustness}

For case 1 , the simulation warm-up period (for steady state simulation) was set to 15,000 hours(run length of 50,000 hours and 30 simulation replications) were used in conducting the experiments, while in case 2 , the simulation warm-up period was set to 480 hours (equivalent to four production weeks' period, length of 1,200 hours, and 30 simulation replications). The inventory at each machine and buffer for each stage were considered in determining the average total work-in-process inventory in both cases. The results from the optimisation experiments for each examined PCS+KAP are provided in Tables 8 and 9. The tables show the average total WIP achieved at 95\%, 98\% and 100\% service levels. Furthermore, the tables provide details for $95 \%$ confidence interval half-width of the average total work-in-process inventory for each PCS+KAP. 


\begin{tabular}{|c|c|c|c|c|}
\hline PCS & \multicolumn{2}{|c|}{ HK-CONWIP } & \multicolumn{2}{c|}{ BK-CONWIP } \\
\hline KAP & D-KAP & S-KAP & D-KAP & S-KAP \\
\hline Average Total WIP at 95\% SL & $32.20 \pm 0.263$ & $32.10 \pm 0.248$ & $31.63 \pm 0.242$ & $30.05 \pm 0.229$ \\
\hline Average Total WIP at 98\% SL & $41.57 \pm 0.266$ & $39.30 \pm 0.254$ & $37.37 \pm 0.248$ & $36.54 \pm 0.242$ \\
\hline Average Total WIP at $100 \% \mathrm{SL}$ & $54.57 \pm 0.291$ & $54.02 \pm 0.273$ & $52.30 \pm 0.263$ & $51.40 \pm 0.251$ \\
\hline
\end{tabular}

Table 8. Case-1 Optimisation results of PCS+KAP for average total WIP with $95 \%$ confidence interval half widths at targeted service levels (SL)

\begin{tabular}{|c|c|c|c|c|}
\hline PCS & \multicolumn{2}{|c|}{ HK-CONWIP } & \multicolumn{2}{c|}{ BK-CONWIP } \\
\hline KAP & D-KAP & S-KAP & D-KAP & S-KAP \\
\hline Average Total WIP at 95\% SL & $1148.38 \pm 4.607$ & $1146.93 \pm 4.353$ & $887.37 \pm 4.065$ & $874.32 \pm 3.817$ \\
\hline Average Total WIP at 98\% SL & $1308.35 \pm 4.753$ & $1304.23 \pm 4.837$ & $965.41 \pm 4.452$ & $961.90 \pm 4.114$ \\
\hline Average Total WIP at $100 \% \mathrm{SL}$ & $1475.43 \pm 4.960$ & $1473.13 \pm 4.833$ & $1175.47 \pm 4.697$ & $1125.03 \pm 4.378$ \\
\hline
\end{tabular}

Table 9. Case-2 Optimisation results of PCS+KAP for average total WIP with $95 \%$ confidence interval half widths at targeted service levels (SL)

The evaluation of the data presented in Tables 8 and 9 (average total WIP) showed that BK-CONWIP S-KAP maintained the lowest amount of the production authorisation cards and the least work-in-process inventory in the systems. BK-CONWIP S-KAP was the superior strategy over the alternatives owing to it capability of using a lower quantity of production authorisation cards to maintain the least average total WIP at targeted service levels. To confirm the observation from Tables 8 and 9, an all pairwise comparison was used to select a superior PCS+KAP with overall $95 \%$ confidence level for six comparisons, such that an individual confidence level is adjusted to $99.17 \%$ confidence level using the Bonferroni Approximation. The difference between the mean of the samples ( $t$-statistics) and the confidence interval for the $t$-statistics were determined. Table 10 presents a description of the comparisons of the confidence interval of the differences pairs of PCS+KAP for case 1 and 2 at $95 \%, 98 \%$ and $100 \%$ service levels. A negative confidence interval without zero between the upper and lower bounds indicates that the PCS+KAP identified by the column label has a statistically significantly smaller proportion of average total WIP than the PCS+KAP identified by the row label. 


\begin{tabular}{|c|c|c|c|c|}
\hline Case 1 & $P C S+K A P$ & HK-CONWIP S-KAP & BK-CONWIP D-KAP & BK-CONWIP S-KAP \\
\hline \multirow{3}{*}{ WIP at $95 \%$ SL } & HK-CONWIP D-KAP & $-0.0992 \pm 0.0208$ & $-0.5689 \pm 0.0291$ & $-2.1483 \pm 0.0458$ \\
\hline & HK-CONWIP S-KAP & - & $-0.4697 \pm 0.0083$ & $-2.0491 \pm 0.0250$ \\
\hline & BK-CONWIP D-KAP & - & - & $-1.5794 \pm 0.0167$ \\
\hline \multirow{3}{*}{ WIP at $98 \% \mathrm{SL}$} & HK-CONWIP D-KAP & $-2.2694 \pm 0.0167$ & $-4.1991 \pm 0.0250$ & $-5.0287 \pm 0.0333$ \\
\hline & HK-CONWIP S-KAP & - & $-1.9297 \pm 0.0083$ & $-2.7594 \pm 0.0167$ \\
\hline & BK-CONWIP D-KAP & - & - & $-0.8297 \pm 0.0083$ \\
\hline \multirow{3}{*}{ WIP at $100 \% \mathrm{SL}$} & HK-CONWIP D-KAP & $-0.5491 \pm 0.0250$ & $-2.2686 \pm 0.0375$ & $-3.1680 \pm 0.0541$ \\
\hline & HK-CONWIP S-KAP & - & $-1.7195 \pm 0.0125$ & $-2.6189 \pm 0.0291$ \\
\hline & BK-CONWIP D-KAP & - & - & $-0.8994 \pm 0.0167$ \\
\hline Case 2 & $P C S+K A P$ & HK-CONWIP S-KAP & BK-CONWIP D-KAP & BK-CONWIP S-KAP \\
\hline \multirow{3}{*}{ WIP at $95 \% \mathrm{SL}$} & HK-CONWIP D-KAP & $-1.4357 \pm 0.3423$ & $-260.9820 \pm 0.7292$ & $-274.0190 \pm 1.0623$ \\
\hline & HK-CONWIP S-KAP & - & $-259.5460 \pm 0.3869$ & $-272.5830 \pm 0.7199$ \\
\hline & BK-CONWIP D-KAP & - & - & $-13.0374 \pm 0.03331$ \\
\hline \multirow{3}{*}{ WIP at $98 \% \mathrm{SL}$} & HK-CONWIP D-KAP & $-3.8183 \pm 0.7885$ & $-342.9240 \pm 0.4042$ & $-346.4170 \pm 0.8580$ \\
\hline & HK-CONWIP S-KAP & - & $-339.1060 \pm 0.9157$ & $-342.5990 \pm 1.2130$ \\
\hline & BK-CONWIP D-KAP & - & - & $-3.4928 \pm 0.4538$ \\
\hline \multirow{3}{*}{ WIP at $100 \%$ SL } & HK-CONWIP D-KAP & $-2.0583 \pm 0.3054$ & $-299.9460 \pm 0.3542$ & $-350.3700 \pm 0.7828$ \\
\hline & HK-CONWIP S-KAP & - & $-297.8880 \pm 0.3071$ & $-348.312 \pm 0.6564$ \\
\hline & BK-CONWIP D-KAP & - & - & $-50.4240 \pm 0.4286$ \\
\hline
\end{tabular}

Table 10. Confidence interval of differences between average total WIP of PCS+KAP

\begin{tabular}{|c|c|c|c|c|}
\hline Case 1 & HK-CONWIP D-KAP & HK-CONWIP S-KAP & BK-CONWIP D-KAP & BK-CONWIP S-KAP \\
\hline WIP at 95\% SL & 4 & 3 & 2 & 1 \\
\hline WIP at 98\% SL & 4 & 3 & 2 & 1 \\
\hline WIP at $100 \% \mathrm{SL}$ & 4 & 3 & 2 & 1 \\
\hline Case 2 & HK-CONWIP D-KAP & HK-CONWIP S-KAP & BK-CONWIP D-KAP & BK-CONWIP S-KAP \\
\hline WIP at 95\% SL & 4 & 3 & 2 & 1 \\
\hline WIP at 98\% SL & 4 & 3 & 2 & 1 \\
\hline WIP at $100 \% \mathrm{SL}$ & 4 & 3 & 2 & 1 \\
\hline
\end{tabular}

Table 11. All-pairwise comparison ranking summary

The outcome of the WIP comparison in Table 10 has no zero between the upper and lower bounds of the confidence intervals. Additionally, Table 11 shows a summary of the ranking of the PCS+KAP based on the confidence intervals in Table 10, where 1 is the best performer and 4 is the worst performer. As can be seen from Table 11, the ranking of PCS+KAP was consistent across both cases and the three Service Level Targets with BK-CONWIP S-KAP being selected as the best performer as it maintained the least average total inventory; the second best performer is BK-CONWIP D-KAP; next is HK-CONWIP S-KAP, while HK-CONWIP D-KAP is the worst PCS+KAP in terms of limiting WIP in a system to achieve a targeted Service Level. 
The parameters of Nelson's combined procedure used in this study are as follows: $k=4$ where $k$ is the number of PCS+KAP for screening and selection. The original number of replication is represented by $n_{0}$, where $n_{0}=30$. The variance of the sample data is denoted as $S_{i}^{2}$, while $\bar{Y}_{i}$ is the mean of the sample data. $W_{i j}=t\left(\frac{s_{i}^{2}}{n_{0}}+\frac{s_{j}^{2}}{n_{0}}\right)^{0.5}$, where $t=2.5336$ The overall confidence level $(\alpha)$ is $90 \%$ for the combined procedure, that is $\alpha=0.1$, also confidence level of $95 \%$ for each of the two stage sampling procedures is given as $\alpha_{0}=\alpha_{1}=\frac{\alpha}{2}=0.05$. A significant difference of 0.2 units for case 1 and 30 boxes for case 2 were selected. Rinott's integral $h$ is given as $h=3.129$. The summary of the results from application of the Nelson's two sampling procedure is presented in Table 12.

\begin{tabular}{|c|c|c|c|c|}
\hline \multirow{2}{*}{ PCS+KAP } & \multicolumn{2}{|c|}{ Case-1 } & \multicolumn{2}{c|}{ Case-2 } \\
\cline { 2 - 5 } & Average Total WIP & $\begin{array}{c}\text { Average Total Service } \\
\text { Level }\end{array}$ & $\begin{array}{c}\text { Average Total Service } \\
\text { Level }\end{array}$ \\
\hline BK-CONWIP S-KAP & Keep & Keep & Keep & Keep \\
\hline BK-CONWIP D-KAP & Eliminate & Keep & Eliminate & Keep \\
\hline HK-CONWIP S-KAP & Eliminate & Keep & Eliminate & Keep \\
\hline HK-CONWIP D-KAP & Eliminate & Keep & Eliminate & Keep \\
\hline
\end{tabular}

Table 12. Summary from application of Nelson's combined procedure for selection of best PCS+KAP

The results of the Nelson's two sample screening and selection procedure show that BK-CONWIP S-KAP was the only survivor of the screening for total WIP in both cases. The outcomes of the screening for total service level in both cases show that all PCS+KAP survived the screening because it was based on a $100 \%$ targeted service level. However, when the work-in-process inventory level required to achieve a $100 \%$ service level was examined BK-CONWIP S-KAP was selected as superior to the alternatives. Therefore, in multi-product manufacturing environments with negligible environmental variability, BK-CONWIP S-KAP should be selected and implemented for the best performance.

\subsection{Analysis of Bottleneck Locations}

The statistics of incoming WIP of each stage and the status of a stage's machine(s) are presented in Tables 13 and 14 for case 1 and case 2 respectively. In case 1, the stages were observed (Table 13) to be readily available with no internal bottleneck, such that the relationship between the proportion of average work-in-process inventory and the availability of the stages does not show that the any stage significantly slowed down the flow of parts in the system. In effect the demand process is the bottleneck as each production stage has unused capacity ( 11 to $12 \%$ idle time). 
This could be attributed to low to moderate demand variations, negligible set-up times and the global demand information transmission method in BK-CONWIP and HK-CONWIP. Olaitan and Geraghty (2013) observed a similar outcome in BSCS and CONWIP and suggested that it was due to global demand information transmission by BSCS and CONWIP. In case 2, the bottleneck was detected at stage three for all PCS+KAP. Observation from the simulation shows that the demand variations, more product variants (products 3 and 4) entering the system at this stage, job section based on a priority rule and a minimum run/batch quantity in place at this stage contributed to the location of the bottleneck in stage three.

\begin{tabular}{|c|c|c|c|c|c|c|}
\hline & & \multirow{2}{*}{$\begin{array}{l}\text { Location of WIP } \\
\text { in Figure } 1\end{array}$} & \multicolumn{2}{|c|}{ HK-CONWIP } & \multicolumn{2}{|c|}{ BK-CONWIP } \\
\hline & & & D-KAP & S-KAP & D-KAP & S-KAP \\
\hline \multirow{5}{*}{ Stage 1} & Incoming WIP & $R M^{1 \& 2}$ & 1.00 & 1.00 & 1.00 & 1.00 \\
\hline & M/c Busy Time & & 0.79 & 0.80 & 0.80 & 0.79 \\
\hline & M/c Idle Time & & 0.12 & 0.11 & 0.10 & 0.11 \\
\hline & M/c Blockage Time & & 0.00 & 0.00 & 0.00 & 0.00 \\
\hline & M/c Shutdown Time & & 0.09 & 0.09 & 0.10 & 0.10 \\
\hline \multirow{5}{*}{ Stage 2} & Incoming WIP & $I_{1}^{1 \& 2}$ & 11.67 & 11.15 & 10.92 & 11.13 \\
\hline & M/c Busy Time & & 0.79 & 0.80 & 0.79 & 0.79 \\
\hline & M/c Idle Time & & 0.10 & 0.11 & 0.12 & 0.11 \\
\hline & M/c Blockage Time & & 0.00 & 0.00 & 0.00 & 0.00 \\
\hline & M/c Shutdown Time & & 0.11 & 0.09 & 0.09 & 0.10 \\
\hline \multirow{5}{*}{ Stage 3} & Incoming WIP & $I_{2}^{1 \& 2}$ & 12.88 & 12.76 & 9.83 & 9.32 \\
\hline & M/c Busy Time & & 0.79 & 0.79 & 0.79 & 0.79 \\
\hline & M/c Idle Time & & 0.12 & 0.12 & 0.11 & 0.12 \\
\hline & M/c Blockage Time & & 0.00 & 0.00 & 0.00 & 0.00 \\
\hline & M/c Shutdown Time & & 0.09 & 0.09 & 0.10 & 0.09 \\
\hline \multicolumn{2}{|c|}{ Final goods inventory } & $I_{3}^{1 \& 2}$ & 30.02 & 30.11 & 31.55 & 30.95 \\
\hline \multicolumn{2}{|r|}{ Total WIP } & & 54.57 & 54.02 & 52.3 & 51.4 \\
\hline
\end{tabular}

M/c: Machine; Busy Time: Time M/c utilised in processing parts + Set-up time (if any); Idle Time: Time when M/c is available but unused; Blockage Time: Time when $\mathrm{M} / \mathrm{c}$ is unavailable due to subsequent stage; Shutdown Time: Maintenance time.

Table 13. Case 1 stage state statistics of PCS+KAP at targeted $100 \%$ service level 


\begin{tabular}{|c|c|c|c|c|c|c|}
\hline & & \multirow{2}{*}{$\begin{array}{l}\text { Location of WIP } \\
\text { in Figure } 2\end{array}$} & \multicolumn{2}{|c|}{ HK-CONWIP } & \multicolumn{2}{|c|}{ BK-CONWIP } \\
\hline & & & D-KAP & S-KAP & D-KAP & S-KAP \\
\hline \multirow{6}{*}{ Stage 1} & Incoming WIP & $R M^{1 \& 2}$ & 479.05 & 433.85 & 327.23 & 324.02 \\
\hline & M/c Busy Time & & 0.82 & 0.82 & 0.80 & 0.80 \\
\hline & M/c Idle Time & & 0.06 & 0.05 & 0.08 & 0.07 \\
\hline & M/c Blockage Time & & 0.00 & 0.00 & 0.00 & 0.00 \\
\hline & M/c Shutdown Time & & 0.06 & 0.07 & 0.06 & 0.07 \\
\hline & M/c Off-Shift Time & & 0.06 & 0.06 & 0.06 & 0.06 \\
\hline \multirow{6}{*}{ Stage 2} & Incoming WIP & $I_{1}^{1 \& 2}$ & 94.10 & 83.99 & 83.75 & 80.01 \\
\hline & M/c Busy Time & & 0.64 & 0.64 & 0.62 & 0.62 \\
\hline & M/c Idle Time & & 0.24 & 0.23 & 0.26 & 0.25 \\
\hline & M/c Blockage Time & & 0.00 & 0.00 & 0.00 & 0.00 \\
\hline & M/c Shutdown Time & & 0.06 & 0.07 & 0.06 & 0.07 \\
\hline & M/c Off-Shift Time & & 0.06 & 0.06 & 0.06 & 0.06 \\
\hline \multirow{6}{*}{ Stage 3} & Incoming WIP & $I_{2}^{1 \& 2}+R M^{3 \& 4}$ & 621.23 & 551.83 & 457.86 & 448.14 \\
\hline & M/c Busy Time & & 0.89 & 0.88 & 0.89 & 0.88 \\
\hline & M/c Idle Time & & 0.00 & 0.02 & 0.01 & 0.02 \\
\hline & M/c Blockage Time & & 0.00 & 0.00 & 0.00 & 0.00 \\
\hline & M/c Shutdown Time & & 0.05 & 0.04 & 0.04 & 0.04 \\
\hline & M/c Off-Shift Time & & 0.06 & 0.06 & 0.06 & 0.06 \\
\hline \multirow{6}{*}{ Stage 4} & Incoming WIP & $I_{3}^{1,2,3 \& 4}$ & 6.27 & 5.94 & 5.48 & 5.62 \\
\hline & M/c Busy Time & & 0.75 & 0.77 & 0.76 & 0.76 \\
\hline & M/c Idle Time & & 0.14 & 0.13 & 0.14 & 0.15 \\
\hline & M/c Blockage Time & & 0.00 & 0.00 & 0.00 & 0.00 \\
\hline & M/c Shutdown Time & & 0.05 & 0.04 & 0.04 & 0.03 \\
\hline & M/c Off-Shift Time & & 0.06 & 0.06 & 0.06 & 0.06 \\
\hline \multirow{6}{*}{ Stage 5} & Incoming WIP & $I_{4}^{1,2,3 \& 4}$ & 6.27 & 5.94 & 5.48 & 5.62 \\
\hline & M/c Busy Time & & 0.75 & 0.77 & 0.76 & 0.76 \\
\hline & M/c Idle Time & & 0.14 & 0.13 & 0.14 & 0.15 \\
\hline & M/c Blockage Time & & 0.00 & 0.00 & 0.00 & 0.00 \\
\hline & M/c Shutdown Time & & 0.05 & 0.04 & 0.04 & 0.03 \\
\hline & M/c Off-Shift Time & & 0.06 & 0.06 & 0.06 & 0.06 \\
\hline \multicolumn{2}{|c|}{ Final goods (super market) WIP } & $I_{5}^{1,2,3 \& 4}$ & 268.51 & 391.58 & 295.67 & 261.62 \\
\hline & Total WIP & & 1475.43 & 1473.13 & 1175.47 & 1125.03 \\
\hline
\end{tabular}

M/c: Machine; Busy Time: Time M/c utilised in processing parts + Set-up time (if any); Idle Time: Time when M/c is available but unused; Blockage Time: Time when $\mathrm{M} / \mathrm{c}$ is unavailable due to subsequent stage; Shutdown Time: Maintenance time; Off-Shift Time: Operator break times.

Table 14. Case 2 stage state statistics of PCS+KAP at targeted $100 \%$ service level 


\subsection{Analysis of Performance with Consideration for Robustness}

In designing a system, various uncertainties are taken in consideration such as environmental and system variability. An environmental variability refers to factors that are externally induced, for instance the rate of ordering a product may vary with respect to time. On the other hand, system variability refers to factors that occur internally in a system, for instance the failure rate of a machine increases and is no longer modelled by the assumed distribution. Considerations were given to in-process changes or failure rate in a system and demand variability as potential factors in carrying out this robustness analysis. The factors were varied within the range of \pm 5 of the simulated values. The experiment was designed with ten factors in both cases 1 and 2, such that four of the ten factors are considered as demand variability and six accounts for processing rate variability. Tables 15 and 16 provide details of the boundary conditions containing the base values, the minimum range values and the maximum range values of the ten factors used in the design of the LHS experiment in case-1, while Tables 17 and 18 present the details of the boundary conditions for case-2. One hundred samples were selected from each of the factors within the -5 to +5 per cent range of the base value. In case-1, the run length of 50000 hours and 30 replications were applied in carrying out the simulation of the 100 samples and a run length of 10 weeks period and 30 replications were used in case-2. JMP design of experiment software (http://www.jmp.com/uk/index.shtml) from SAS was used to design the experiments in accordance with the Latin hypercube sampling technique. ModelRisk from Vose Software (http://www.vosesoftware.com/) was used to conduct the analysis for the stochastic dominance tests.

\begin{tabular}{|c|c|c|}
\hline Demand (Environmental Variability) Factor & Product 1 & Product 2 \\
\hline Mean (Normal Distribution) & $5.61[5.26,5.96]$ & $5.72[5.65,5.79]$ \\
\hline Standard Deviation (Normal Distribution) & $2.805[2.52,3.09]$ & $0.572[0.29,0.86]$ \\
\hline
\end{tabular}

[R.V]: Range values for the Factors (range from $-5 \%$ to $+5 \%$ of base value).

Table 15. Case-1 boundary conditions used in creating LHS samples

\begin{tabular}{|c|c|c|c|}
\hline Processing (System variability) Factor & Stage 1 & Stage 2 & Stage 3 \\
\hline $\begin{array}{c}\text { Mean Time before Failure } \\
\text { (Exponential Distribution) }\end{array}$ & $90[78.5,103]$ & $90[78.5,103]$ & $90[78.5,103]$ \\
\hline $\begin{array}{l}\text { Mean Time before Failure } \\
\text { (Exponential Distribution) }\end{array}$ & $10[8.72,11.5]$ & $10[8.72,11.5]$ & $10[8.72,11.5]$ \\
\hline
\end{tabular}

[R.V]: Range values for the Factors (range from $-5 \%$ to $+5 \%$ of base value).

Table 16. Case-1 boundary conditions used in creating LHS samples 1 


\begin{tabular}{|c|c|c|}
\hline Factors/Stages & Stages 1 \& 2 & Stages 3, 4 \& 5 \\
\hline $\begin{array}{c}\text { Mean time before Failure } \\
\text { (Exponential Distribution) }\end{array}$ & $3.5[3.05,4.01]$ & $6.1[5.32,6.99]$ \\
\hline $\begin{array}{c}\text { Mean time to repair } \\
\text { (Exponential Distribution) }\end{array}$ & $0.23[0.21,0.26]$ & $0.23[0.21,0.26]$ \\
\hline $\begin{array}{c}\text { Changeover: Mean } \\
\text { (Normal Distribution) }\end{array}$ & $\mathrm{N} / \mathrm{A}$ & $0.3267[0.3130,0.3404]$ \\
\hline $\begin{array}{c}\text { Changeover: Standard Deviation } \\
\text { (Normal Distribution) }\end{array}$ & $\mathrm{N} / \mathrm{A}$ & $0.1088[0.0915,0.1242]$ \\
\hline
\end{tabular}

N/A: Not Applicable; [R.V]: Range values for the Factors (range from $-5 \%$ to $+5 \%$ of base value).

Table 17. Case-2 boundary conditions used in creating LHS samples

\begin{tabular}{|c|c|c|c|c|c|c|c|}
\hline Product & Range Setting & Week 1 & Week 2 & Week 3 & Week 4 & Week 5 & Week 6 \\
\hline \multirow{3}{*}{1} & Base value & 115 & 194 & 128 & 143 & 169 & 137 \\
\hline & $-5 \%$ of Base & 109 & 184 & 122 & 136 & 161 & 130 \\
\hline & $+5 \%$ of Base & 121 & 204 & 134 & 150 & 177 & 144 \\
\hline \multirow{3}{*}{2} & Base value & 121 & 158 & 131 & 62 & 61 & 51 \\
\hline & $-5 \%$ of Base & 115 & 150 & 124 & 59 & 58 & 48 \\
\hline & $+5 \%$ of Base & 127 & 166 & 138 & 65 & 64 & 54 \\
\hline \multirow{3}{*}{3} & Base value & 503 & 366 & 413 & 365 & 381 & 480 \\
\hline & $-5 \%$ of Base & 478 & 348 & 392 & 347 & 362 & 456 \\
\hline & $+5 \%$ of Base & 528 & 384 & 434 & 383 & 400 & 504 \\
\hline \multirow{3}{*}{4} & Base value & 147 & 212 & 147 & 108 & 112 & 144 \\
\hline & $-5 \%$ of Base & 140 & 201 & 140 & 103 & 106 & 137 \\
\hline & $+5 \%$ of Base & 154 & 223 & 154 & 113 & 118 & 151 \\
\hline
\end{tabular}

Table 18. Case-2 boundary conditions used in creating LHS samples demand data set

The average total service level and average total work-in-process inventory are the performance metrics used in the comparison of the pull production control strategies (HK-CONWIP and BK-CONWIP) and Kanban allocation policies (S-KAP and D-KAP) investigated. An incremental range of $5 \%$ was applied in constructing the cumulative distribution function plots of the average total service level of each of the two systems. The comparison of the strategies was conducted for the entire distribution in order to give consideration to achieving service level because of high or low work-in-process inventory in the system. Figures 5 and 6 provide descriptions of the cumulative average total service level in cases 1 and 2 respectively. 


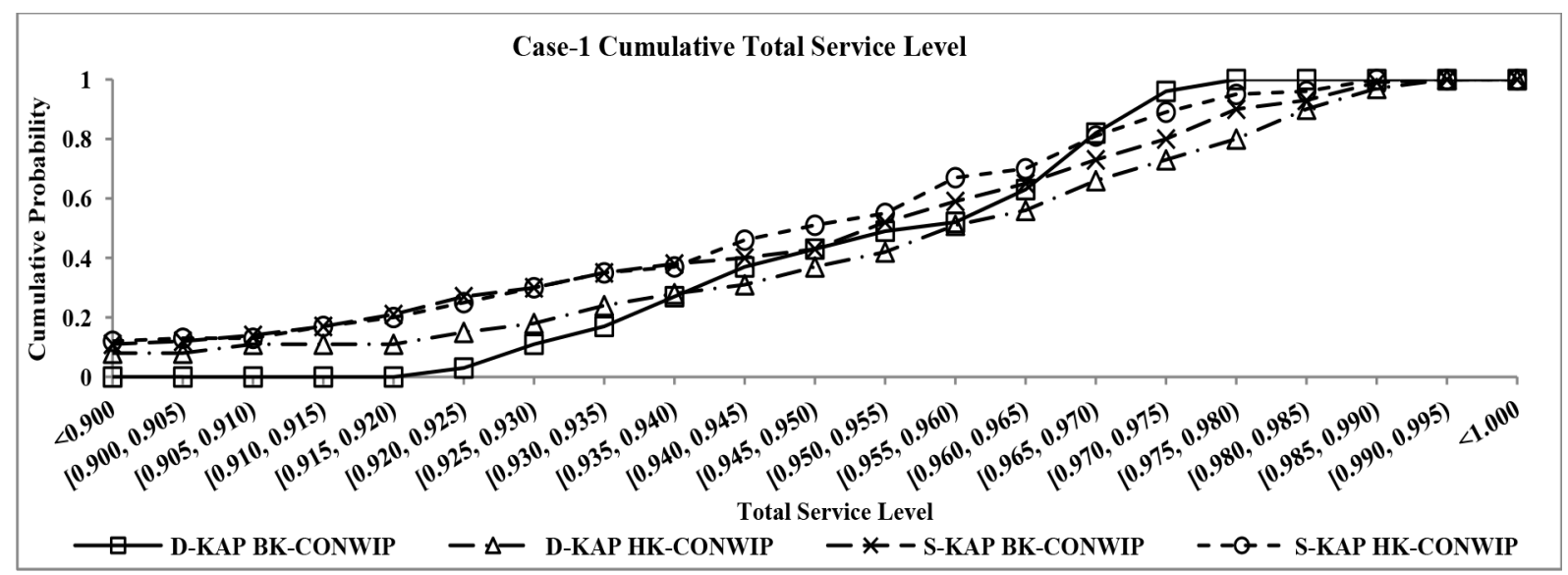

Figure 5. Case-1 cumulative distribution function plot of total service level

The result of the average total service level stochastic dominance test and cumulative distribution function plot for case-1 (see, Figure 5) showed first order dominance and second order dominance outcomes. BK-CONWIP D-KAP stochastically dominates HK-CONWIP D-KAP, BK-CONWIP S-KAP and HK-CONWIP S-KAP in a second order dominance. While HK-CONWIP D-KAP has a first order dominance over HK-CONWIP S-KAP and BK-CONWIP S-KAP. BK-CONWIP S-KAP has a second order dominance over HK-CONWIP S-KAP. Therefore, the ranking of the performance of the strategies and policies in the order of best to worst PCS+KAP is presented as follows: BK-CONWIP D-KAP outperformed all of the alternatives, followed by HK-CONWIP D-KAP, next is BK-CONWIP S-KAP and HK-CONWIP S-KAP is ranked as the worst performer in case-1. Similarly, D-KAP outperformed S-KAP.

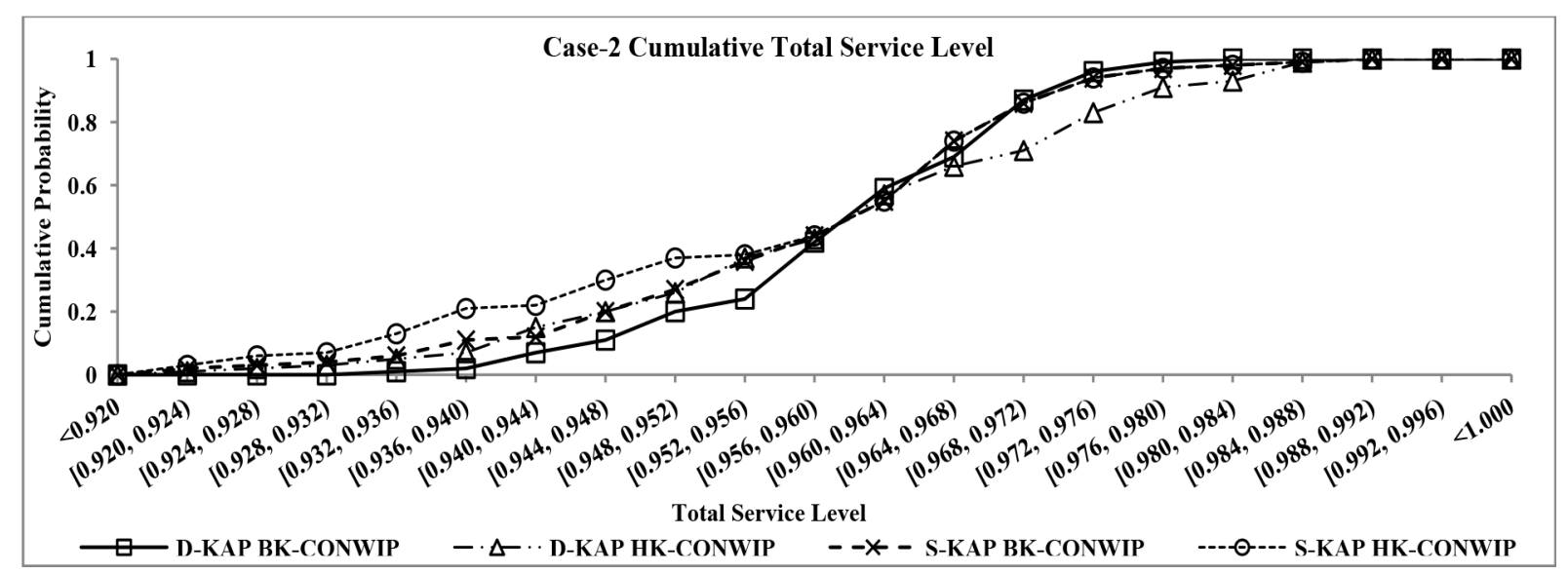

Figure 6. Case-2 cumulative distribution function plot of total service level 
In case-2, the result of the stochastic dominance test and cumulative distribution function plot (see, Figure 6) showed that BK-CONWIP D-KAP has a first order dominance over HK-CONWIP S-KAP and second degree dominance over BK-CONWIP S-KAP and HK-CONWIP D-KAP. Conversely, HK-CONWIP D-KAP had second degree dominance over BK-CONWIP S-KAP and HK-CONWIP S-KAP. BK-CONWIP S-KAP has a second order dominance over HK-CONWIP S-KAP. The ranking on performance of the strategies for case- 2 based on a robustness level of $\pm 5 \%$ range in the system is shown as follows: BK-CONWIP D-KAP outperformed the alternative strategies/policies and was ranked the best, followed by HK-CONWIP D-KAP, then BK-CONWIP $\mathrm{S}-\mathrm{KAP}$, while HK-CONWIP S-KAP is ranked as the worst performer in case-2.

The results of the average total work-in-process inventory when robustness was considered in the systems (see, Figures 7 to 10) indicated that HK-CONWIP (D-KAP and S-KAP) maintained high level of work-in-process inventory when compared to the level of work-in-process inventory achieved by BK-CONWIP (D-KAP and S-KAP). Therefore, HK-CONWIP (D-KAP and S-KAP) is the least desired strategy in both cases. BK-CONWIP S-KAP had the least total average work-in-process inventory in both case-1 and case-2, implying that it is a better choice when the level of work-in-process inventory is considered as a deciding factor for the selection of a strategy and policy for systems prone to environmental variability. Conversely, HK-CONWIP D-KAP had the highest level of work-in-process inventory in both case 2, signifying that it was the worst strategy in terms of work-in-process inventory under environmental and system variability. In both systems, it was observed that BK-CONWIP in S-KAP mode is superior to the alternatives. HK-CONWIP in D-KAP mode is inferior to the alternatives. BK-CONWIP D-KAP ranked second with lower work-in-process inventory level than HK-CONWIP S-KAP and HK-CONWIP D-KAP, whereas HK-CONWIP S-KAP ranked third with lower work-in-process inventory than HK-CONWIP D-KAP. Overall, the examination of Figures 7 to 10 showed that BK-CONWIP outperforms HK-CONWIP in both simple and complex systems. S-KAP outperforms D-KAP in both systems under instabilities.

The stochastic dominance test results based on minimisation of the average total work-in-process inventory of the strategies showed that BK-CONWIP S-KAP has first-degree dominance over HK-CONWIP D-KAP, HK-CONWIP S-KAP and BK-CONWIP D-KAP in both case-1 and case-2. In case-1, BK-CONWIP D-KAP has second-degree dominance over HK-CONWIP S-KAP and first-degree dominance over HK-CONWIP D-KAP. HK-CONWIP S-KAP has first-degree dominance over HK-CONWIP D-KAP. The case-2 results showed that BK-CONWIP S-KAP stochastically dominated BK-CONWIP D-KAP, HK-CONWIP S-KAP and HK-CONWIP D-KAP in first-order dominance. Equally, HK-CONWIP S-KAP has first-order dominance over HK-CONWIP D-KAP. Hence, the ranking of the strategies and policies based on robustness level using the average total work-in-process inventory was given as follows: BK-CONWIP S-KAP ranked best in both cases, while BK-CONWIP D-KAP ranked second best in both cases. HK-CONWIP S-KAP ranked third best in both cases, while HK-CONWIP D-KAP ranked fourth (worst) in both cases. 


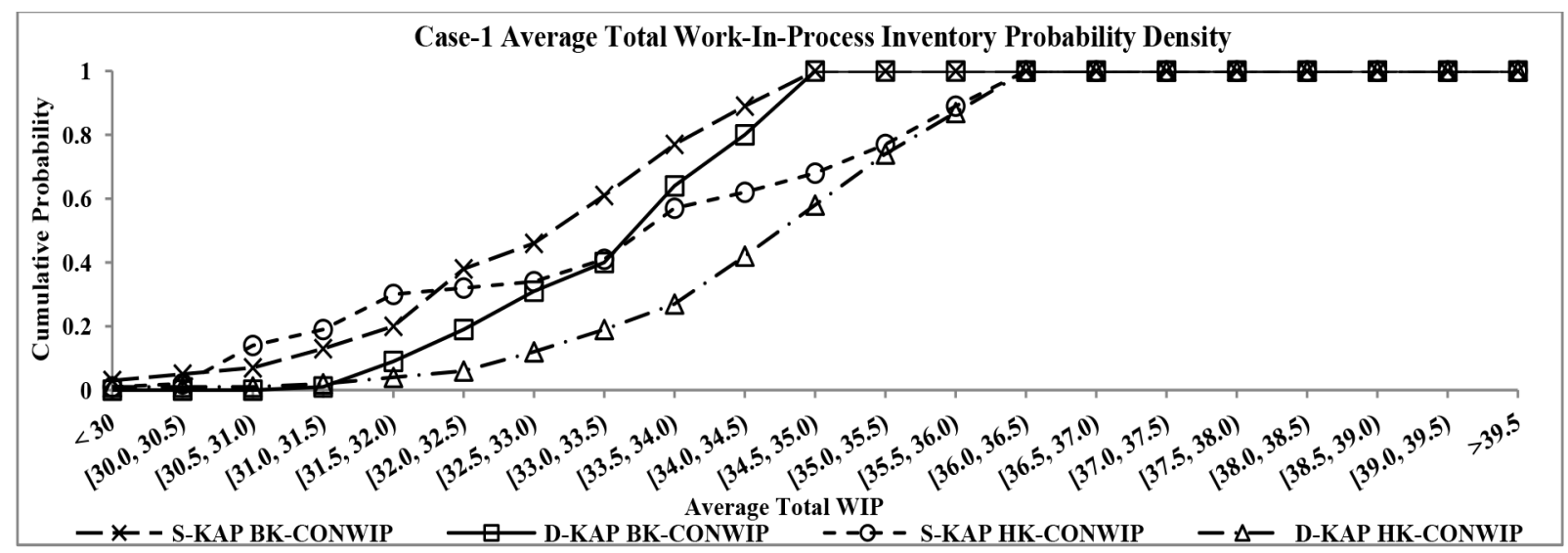

Figure 7. Case-1 cumulative distribution function plot of average total WIP

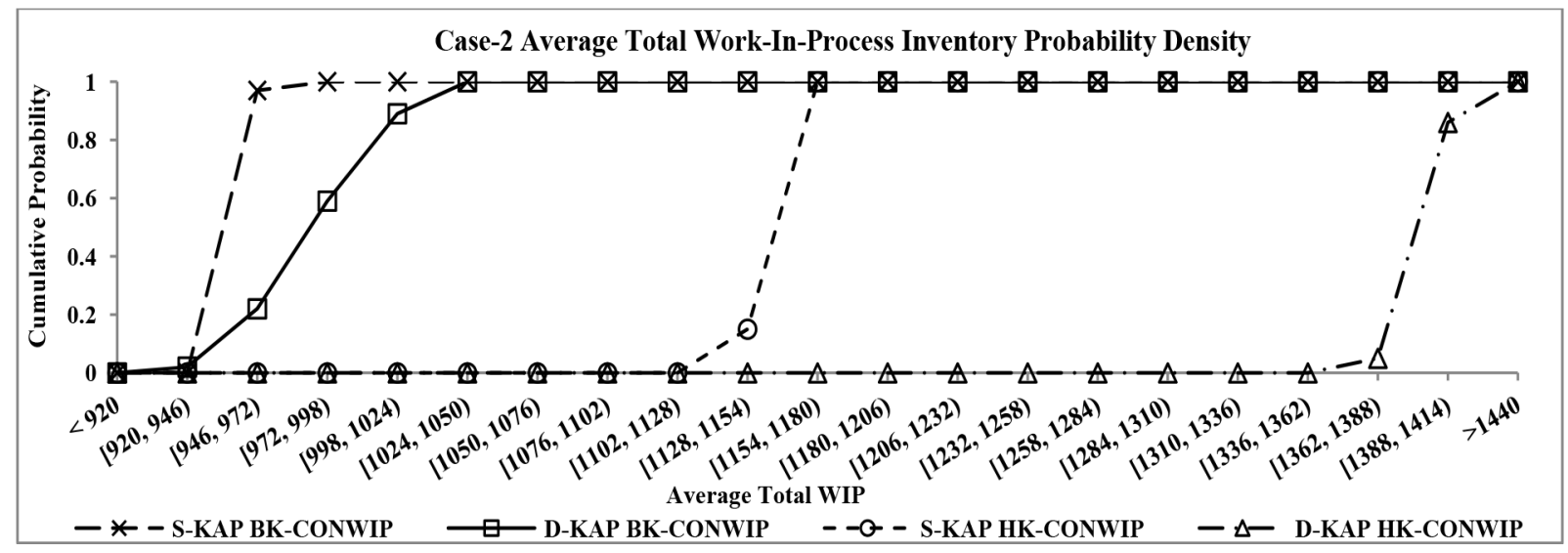

Figure 8. Case-2 cumulative distribution function plot of average total WIP

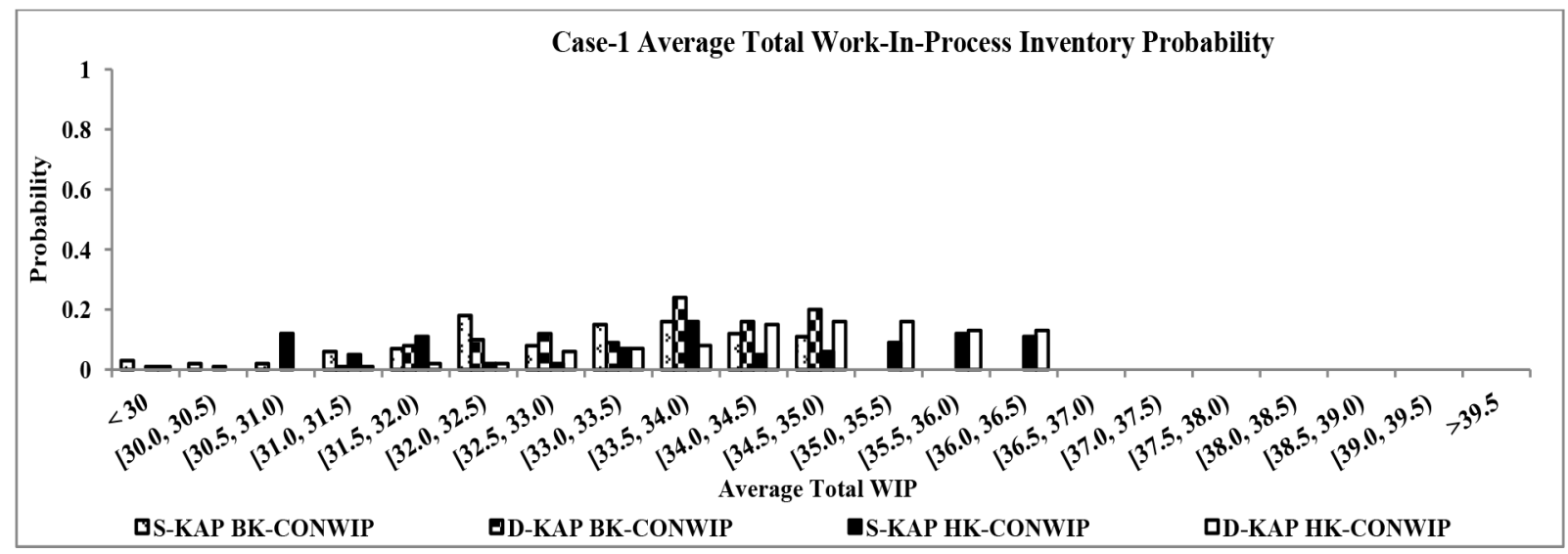

Figure 9. Case-1 average total WIP probability histogram 


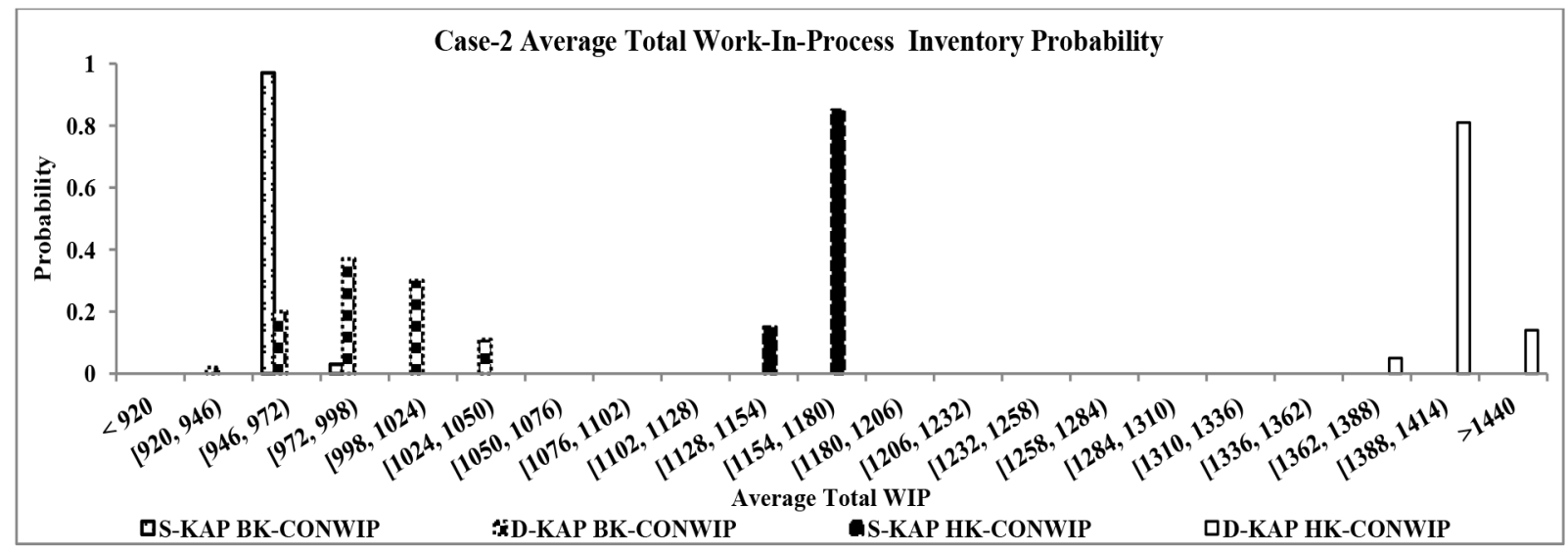

Figure 10. Case-2 average total WIP probability histogram

In general, BK-CONWIP outperformed HK-CONWIP in both average total service level and average total work-in-process inventory in the two cases examined under environmental and system variability, while D-KAP outperformed S-KAP when service level is considered. However, when WIP is considered, S-KAP is superior to D-KAP in both simple and complex manufacturing systems. Tables 19 and 20 provide a summary of the rankings of the PCS+KAP from the robustness analysis experiments for Service Level and WIP, respectively, where 1 indicates the best performer and 4 indicates the worst performer.

\begin{tabular}{|l|c|c|c|c|}
\hline & BK-CONWIP D-KAP & HK-CONWIP D-KAP & BK-CONWIP S-KAP & HK-CONWIP S-KAP \\
\hline Case 1 $(100 \% \mathrm{SL})$ & 1 & 2 & 3 & 4 \\
\hline Case 2 $(100 \% \mathrm{SL})$ & 1 & 2 & 3 & 4 \\
\hline
\end{tabular}

Table 19. Summary of robustness analysis ranking for Service Level (SL)

\begin{tabular}{|c|c|c|c|c|}
\hline & BK-CONWIP S-KAP & BK-CONWIP D-KAP & HK-CONWIP S-KAP & HK-CONWIP D-KAP \\
\hline Case 1 (WIP) & 1 & 2 & 3 & 4 \\
\hline Case 2 (WIP) & 1 & 2 & 3 & 4 \\
\hline
\end{tabular}

Table 20. Summary of robustness analysis ranking for WIP 


\section{Discussion}

Direct observation of the Pareto Frontier curves generated from the multi-objective optimisations for both cases (Figures 3 and 4 ) shows that BK-CONWIP required less total inventory (WIP) to achieve any targeted Service Level in the range $90 \%$ to $100 \%$. Also, from direct observation of the Pareto Frontier curves it is clear that a PCS operating S-KAP will achieve a target service level with less (or at worst equivalent) WIP than when operating D-KAP. For the simple system studied in case-1 this difference is maintained across the range for BK-CONWIP and is apparent for Service Levels above $95 \%$ for HK-CONWIP. For the more complex system studied in case- 2 this difference is observably significant for both BK-CONWIP and HK-CONWIP for Service Levels below 95\% and more modest for higher Service Levels. It was, therefore, necessary to consider whether these differences in performances are statistically significant, especially for a given PCS operating S-KAP and D-KAP and if so, which PCS+KAP combination is the best performer. The results of the all-pairwise comparisons in both cases found statistically significant differences between all pairs of PCS+KAP for both cases for WIP required to achieve service levels of $95 \%, 98 \%$ and $100 \%$. It is also possible to conclude from the all-pairwise comparisons that S-KAP outperformed D-KAP and BK-CONWIP outperformed HK-CONWIP in all instances. The application of the ranking and selection procedure confirmed this by selecting BK-CONWIP operating S-KAP as the superior PCS+KAP in both cases for a targeted Service Level of $100 \%$. The selection of S-KAP as being the preferred Kanban allocation policy for a PCS is only applicable to stable production systems with steady demand pattern.

It is observable from the results presented in Table 10 that the magnitudes of the differences between the performances of a PCS in S-KAP mode and D-KAP mode, while statistically significant, were modest in comparison to the magnitudes of the differences between the performances of BK-CONWIP and HK-CONWIP irrespective of KAP applied. But, given that there are fewer parameters to plan (optimise), especially where there are a large number of product types in the system, it is recommended that the implementation of BK-CONWIP in S-KAP mode will minimise WIP inventory rather than D-KAP mode. However, robustness of optimal solutions is required in order to select an appropriate PCS+KAP for a system prone to instability especially when service level has a higher priority for PCS+KAP selection.

The level of instability in a system influences the performance of PCS+KAP. When a system is prone to environmental changes between a \pm 5 range of the base value, none of the PCS+KAP achieved the $100 \%$ service level target. It was shown that the service level performance of D-KAP was more effective than S-KAP. BK-CONWIP D-KAP was shown to be the superior PCS+KAP. HK-CONWIP D-KAP is the second best performer, followed by BK-CONWIP S-KAP, and the worst performer is HK-CONWIP S-KAP. 
The results of the average total work-in-process inventory (Figures 7 to 10) suggested that HK-CONWIP (D-KAP and S-KAP) is the least desired strategy owing to its high-level of work-in-process inventory. This is attributed to the fact that the control mechanism of HK-CONWIP does not transmit demand information to the internal stages of the line, resulting in slower responses to demand variations and increasing the WIP level. BK-CONWIP S-KAP had the least total average work-in-process inventory and was ranked as the best performer, followed by BK-CONWIP D-KAP. BK-CONWIP outperformed HK-CONWIP in both S-KAP and D-KAP modes owing to its capability to respond to demand variations with high flexibility and low WIP. When robustness of the PCS+KAP is considered with respect to WIP, S-KAP will generally outperform D-KAP for the same PCS. The rankings that resulted from the robustness analysis (see Tables 19 and 20) recommends the selection of BK-CONWIP D-KAP when a high service level is required, while BK-CONWIP S-KAP should be selected when minimisation of the WIP inventory is a priority for PCS+KAP selection.

\subsection{Conclusion}

The findings of this research agree with the works of Onyeocha and Geraghty (2012); Onyeocha et al. (2013a, 2013b), by demonstrating that BK-CONWIP combined with S-KAP has a lower WIP inventory than BK-CONWIP D-KAP. BK-CONWIP is effective in managing the conflicting objectives of maintaining high service levels while minimising total WIP in both the simple and complex multi-product serial assembly lines examined. This was attributed to the global transmission of demand information and the CONWIP's WIP Cap (limiting WIP into a system) rule. Also, the findings in this study support the work of Baynat et al. (2002) by providing evidence that S-KAP is an effective policy for distributing production authorisation cards in multi-product environments when the system (e.g. repair and failure distributions) and environmental (i.e. demand distribution/profile) information used to determine the control parameters of PCS are assumed to be stable.

This study has advanced the work of Onyeocha and Geraghty (2012) and Baynat et al. (2002) by answering the practical question of the robustness of the optimal solution. The optimal solutions achieved in all the PCS+KAP examined demonstrated a high probability of poor service level (Figures 5 and 6 ) when the optimal solutions (which achieved 100\% service level under steady demand and stable system conditions), was subjected to a \pm 5 range of demand and system instabilities. This shows that the selection of a strategy and policy solely on the optimal solution performance is misleading and can result in poor delivery performance. It was shown that selection of a pull control strategy combined with S-KAP performs worse than D-KAP in terms of service level. This was attributed to the fact that D-KAP has a higher number of production authorisation cards resulting in a higher WIP level and further responds to instability than S-KAP. BK-CONWIP D-KAP is selected as the best performer when service 
level is a priority for selection of a strategy and policy. Therefore, if a multi-product serial assembly line is prone to instability it is recommended that BK-CONWIP D-KAP will outperform its alternatives.

This paper is limited to multi-product multi-stage serial lines with deterministic and similar processing times. Complex multi-product systems with stochastic processing times, balancing issues and high demand instability may be useful to demonstrate the efficacy of selection of BK-CONWIP D-KAP over its alternative. Supposedly, BK-CONWIP D-KAP will maintain a high level of delivery performance than its alternatives.

\subsection{Insights for Operations Personnel}

We have extended the method of selection of strategy based on optimal solution to include conducting robustness tests on production control strategies especially, for complex multi-product systems. Also, to identify the Kanban allocation policy that has the most impact on the operational performance of different strategies when WIP or service level is considered in a system prone to instabilities.

The method of comparing the operational performance of complex manufacturing systems by optimising strategies was used in conjunction with the robustness method. The differences in the results support the need for robustness study. The result of the study when robustness was not considered recommends BK-CONWIP S-KAP as the superior PCS+KAP for both performance metrics (WIP and Service level). However, the robustness test shows that the superior PCS+KAP is BK-CONWIP D-KAP when service level is considered for selecting PCS+KAP, while BK-CONWIP S-KAP is recommended when WIP is considered. BK-CONWIP consistently outperformed HK-CONWIP.

The outcomes of this work are applicable to multi-product serial flow lines with negligible/significant setup times. The multi-objective optimisation provides decision support for selection of control-parameters of systems with steady demand and system configuration. However, real-world systems are unstable and it is the opinion of this study that conducting a robustness analysis of the optimal solutions will improve the decision for selection of a control strategy and policy over another. BK-CONWIP S-KAP is recommended for WIP minimisation, while BK-CONWIP D-KAP is favoured for a higher delivery performance. 


\subsection{Further Research Work}

Finally, it was postulated that BK-CONWIP would respond more favourably than other PCS+KAP systems to a certain level of demand variations without recourse to re-planning of control parameters and rescheduling in a system (Onyeocha \& Geraghty, 2012). We therefore, identify this area for further research to verify the level of flexibility of BK-CONWIP with respect to product mix and product demand volume variations in a complex multi-product system.

\section{References}

Akturk, M.S., \& Erhun, F. (1999). An overview of design and operational issues of Kanban systems. International Journal of Production Research, 37(17), 3859-3881. http://dx.doi.org/10.1080/002075499189808

Altiok, T., \& Shiue, G.A. (2000). Pull-type manufacturing systems with multiple product types. IIE Transactions, 32(2), 115-124. http://dx.doi.org/10.1080/07408170008963884

Bard, J.F., \& Golany, B. (1991). Determining the number of Kanbans in a multi-product, multi-stage production system. International Journal of Production Research, 29(5), 881-895. http://dx.doi.org/10.1080/00207549108930108

Baynat, B., Buzacott, J.A., \& Dallery, Y. (2002). Multi-product Kanban-like control systems. International Journal of Production Research, 40(16), 4225-4255. http://dx.doi.org/10.1080/00207540210146198

Bonvik, A.M., \& Gershwin, S.B. (1996). Beyond Kanban: Creating and analyzing lean shop floor control policies. Manufacturing and Service Operations Management Conference proceedings, June, 46-51. Dartmouth College, The Amos Tuck School Hanover, NH, USA.

Bonvik, A.M., Christopher, C., \& Gershwin, S.B. (1997). A comparison of production line control mechanisms. International Journal of Production Research, 35(3), 789-804. http://dx.doi.org/10.1080/002075497195713

Chern, C.C., Lei, S., \& Huang, K. (2014). Solving a multi-objective master planning problem with substitution and a recycling process for a capacitated multi-commodity supply chain network. Journal of Intelligent Manufacturing, 25, 1-25. http://dx.doi.org/10.1007/s10845-012-0667-0

Dasci, A., \& Karakul, M. (2008). Performance evaluation of a single-stage two product manufacturing system operating under pull-type control. Computers and Operations Research, 35(9), 2861-2876. http://dx.doi.org/10.1016/j.cor.2006.12.024 
Duenyas, I. (1994). A simple release policy for networks of queues with controllable inputs. Operations Research, 42(6), 1162-1171. http://dx.doi.org/10.1287/opre.42.6.1162

Feit, E.M., \& Wu, S.D. (2000). Transfer line design with uncertain machine performance information. IEEE Transactions on Robotics and Automation, 16(5), 581-587. http://dx.doi.org/10.1109/70.880807

Feng, W., Zheng, L., \& Li, J. (2011). Multi-product manufacturing systems with sequence-dependent setups: performance evaluation and system properties. In Proceedings of 7th IEEE conference on automation science and engineering, 363-368. Trieste, Italy. http://dx.doi.org/10.1109/case.2011.6042471

Feng, W., Zheng, L., \& Li, J. (2012). The robustness of scheduling policies in multi-product manufacturing systems with sequence-dependent setup times and finite buffers. Computers \& Industrial Engineering, 63(4), 1145-1153. http://dx.doi.org/10.1016/j.cie.2012.05.009

Geraghty, J., \& Heavey, C. (2005). A review and comparison of hybrid and pull-type production control strategies. OR Spectrum, 27(2), 435-457. http://dx.doi.org/10.1007/s00291-005-0204-z

Geraghty, J., \& Heavey, C. (2010). An investigation of the influence of coefficient of variation in the demand distribution on the performance of several lean production control strategies. International Journal of Manufacturing Technology and Management, 20(1-4), 94-119. http://dx.doi.org/10.1504/IJMTM.2010.032894

Gurgur, C.Z., \& Altiok, T. (2008). Decentralized multi-product multi-stage systems with backorders. IIE Transactions, 40(3), 238-251. http://dx.doi.org/10.1080/07408170701488011

Hernandez-Matias, J.C., Vizan, A., Hidalgo, A., \& Rios, J. (2006). Evaluation of techniques for manufacturing process analysis. Journal of Intelligent Manufacturing, 17, 571-583. http://dx.doi.org/10.1007/s10845-006-0025-1

Horn, J. (1997). F1.9 multicriteria decision making. In Back, T., Fogel, D.B., \& Michalewicz, Z. (Eds.), Handbook of Evolutionary Computation. Bristol (UK): Institute of Physics Publishing. http://dx.doi.org/10.1887/0750308958/b386c85

Hum, S.H., \& Lee, C.K. (1998). JIT scheduling rules: a simulation evaluation. Omega, 26(3), 381-395. http://dx.doi.org/10.1016/S0305-0483(97)00066-2

Hwang, C.L., \& Masud, A.S.M. (1979). Multiple Objectives Decision Making Methods and Applications. Berlin: Springer. http://dx.doi.org/10.1007/978-3-642-45511-7

Kang, Y., \& Gershwin, S.B. (2005). Information inaccuracy in inventory systems: stock loss and stock out. IIE Transactions, 37(9), 843-859. http://dx.doi.org/10.1080/07408170590969861 
Kernan, B., \& Geraghty, J. (2004). A multi-objective genetic algorithm for extend. Proceedings of the First Irish Workshop on Simulation in Manufacturing, Services and Logistics, 83-92. Limerick, Ireland.

Khojasteh-Ghamari, Y. (2009) . A performance comparison between Kanban and CONWIP controlled assembly systems. Journal of Intelligent Manufacturing, 20(6), 751-760. http://dx.doi.org/10.1007/s10845-008-0174-5

Kleijnen, J.P.C., \& Gaury, E. (2003). Short-term robustness of production management systems: a cases study. European Journal of Operational Research, 148(2), 452-465. http://dx.doi.org/10.1016/S0377-2217(02)00437-X

Koulouriotis, D.E., Xanthopoulos, A.S., \& Tourassis, V.D. (2010). Simulation optimisation of pull control policies for serial manufacturing lines and assembly manufacturing systems using genetic algorithms. International Journal of Production Research, 48(10), 2887-2912. http://dx.doi.org/10.1080/00207540802603759

Krieg, G.N., \& Kuhn, H. (2004). Analysis of multi-product Kanban systems with state-dependent setups and lost sales. Annals of Operations Research, 125(1-4), 141-166. http://dx.doi.org/10.1023/B:ANOR.0000011189.48656.14

Krieg, G.N., \& Kuhn, H. (2002). A decomposition method for multi-product Kanban systems with setup times and lost sales. IIE Transactions, 34(7), 613-625.

http://dx.doi.org/10.1080/07408170208928898

Krishnamurthy, A., Suri, R., \& Vernon, M. (2004). Re-examining the performance of MRP and Kanban material control strategies for multi-product flexible manufacturing systems. The Journal of Flexible Manufacturing Systems, 16, 123-150.

http://dx.doi.org/10.1023/B:FLEX.0000044837.86194.19

Li, J., \& Huang, N. (2005). Modelling and analysis of a multiple product manufacturing system with split and merge. International Journal of Production Research, 43, 4049-4066. http://dx.doi.org/10.1080/00207540500031899

Li, J., Blumenfeld, D.E., \& Marin, S.P. (2007). Manufacturing system design to improve quality buy rate: an automotive paint shop application study. IEEE Transactions on Automation Science and Engineering, 4(1), 75-79. http://dx.doi.org/10.1109/TASE.2006.872958

Li, J., Blumenfeld, D.E., \& Marin, S.P. (2008). Production system design for quality robustness. IIE Transactions, 40(3), 162-176. http://dx.doi.org/10.1080/07408170601013661

Liberopoulos, G., \& Dallery, Y. (2000). A unified framework for pull control mechanisms in multi-stage manufacturing systems. Annals of Operations Research, 93(1-4), 325-355. http://dx.doi.org/10.1023/A:1018980024795 
Lin, J.T., \& Chen, C. (2015). Simulation optimization approach for hybrid flow shop scheduling problem in semiconductor back-end manufacturing. Simul Model Pract Th, 51, 100-114. http://dx.doi.org/10.1016/j.simpat.2014.10.008

Marek, R.P., Elkins, D.A., \& Smith, D.R. (2001). Understanding the fundamentals of Kanban and CONWIP pull systems using simulation. In Peters, B.A., Smith, J.S., Medeiros, D.J., \& Rohrer, M.W. (Eds.), Proceedings of the 33rd Conference on Winter Simulation, Arlington, Virginia, 9-12 December, Vol. 1, 921-929, IEEE Computing Society. Washington, DC, USA. http://dx.doi.org/10.1109/wsc.2001.977394

Moeeni, F., Sanchez, S.M., \& Vakharia, A.J. (1997). A robust design methodology for Kanban system design. International Journal of Production Research, 35(10), 2821-2838. http://dx.doi.org/10.1080/002075497194462

Nelson, B.L., Swann, J., Goldsman, D., \& Song, W. (2001). Simple procedures for selecting the best simulated system when the number of alternatives is large. Operations Research, 49(6), 950-963. http://dx.doi.org/10.1287/opre.49.6.950.10019

Olaitan, O.A., \& Geraghty, J. (2013). Evaluation of production control strategies for negligiblesetup, multi-product, serial lines with consideration for robustness. Journal of Manufacturing Technology Management, 24(3), 331-357.

http://dx.doi.org/10.1108/17410381311318864

Onyeocha, C.E., \& Geraghty, J. (2012). A modification of the hybrid Kanban-CONWIP production control strategy for multi-product manufacturing systems. In IMC29: International Manufacturing Conference proceedings. Belfast, UK: University of Ulster.

Onyeocha, C.E., Khoury, J., \& Geraghty, J. (2013a). Evaluation of the effect of erratic demand on a multi-product Basestock Kanban-CONWIP control strategy. Proceedings of the 9th Conference on Stochastic Models of Manufacturing and Service Operations. May. Kloster Seeon, Germany.

Onyeocha, C.E., Khoury, J., \& Geraghty, J. (2013b). A comparison of Kanban-like control strategies in a multi-product manufacturing system under erratic demand. In Pasupathy, R., Kim, S.-H., Tolk, A., Hill, R., \& Kuhl, M.E. (Eds.). Proceedings of the 2013 Conference on Winter Simulation, Vol. 1. 2730-2741. IEEE Computing Society. Washington, DC, USA. http://dx.doi.org/10.1109/WSC.2013.6721644

Park, C.W., \& Lee, H.S. (2013). Performance evaluation of a multi-product CONWIP assembly system with correlated external demands. International Journal of Production Economics, 144(1), 334-344. http://dx.doi.org/10.1016/j.ijpe.2013.02.021 
Ryan, S.M., \& Vorasayan, J. (2005). Allocating work in process in multi-product conwip system with lost sales. International Journal of Production Research, 43(2), 223-246. http://dx.doi.org/10.1080/0020754042000268875

Ryan, S.M., Baynat, B., \& Choobineh, F. (2000). Determining inventory levels in a CONWIP controlled job shop. IIE Transactions, 32(2), 105-114.

http://dx.doi.org/10.1080/07408170008963883

Saitou, K., Malpathak, S., \& Qvam, H. (2002). Robust design of flexible manufacturing systems using colored Petri net and genetic algorithm. Journal of Intelligent Manufacturing, 13(5), 339-351. http://dx.doi.org/10.1023/A:1019920324813

Satyam, K., \& Krishnamurthy, A. (2008). Performance evaluation of a multi-product system under CONWIP control. IIE Transactions, 40(3), 252-264.

http://dx.doi.org/10.1080/07408170701488086

Spearman, M.L., Woodruff, D., \& Hopp, W. (1990). CONWIP: a pull alternative to Kanban. International Journal of Production Research, 28, 879-894.

http://dx.doi.org/10.1080/00207549008942761

Taguchi, G. (1987). System of experimental design: Engineering methods to optimize quality and minimize costs. Vol. 1. Michigan, USA: UNIPUB/Krauss International.

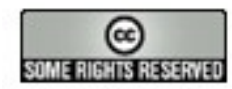

Article's contents are provided on a Attribution-Non Commercial 3.0 Creative commons license. Readers are allowed to copy, distribute and communicate article's contents, provided the author's and Journal of Industrial Engineering and Management's names are included. It must not be used for commercial purposes. To see the complete license contents, please visit http://creativecommons.org/licenses/by-nc/3.0/. 